University of Wollongong

Research Online

Faculty of Engineering and Information

Faculty of Engineering and Information

Sciences - Papers: Part A

Sciences

$1-1-2015$

\title{
Microstructures and mechanical properties of dual phase steel produced by laboratory simulated strip casting
}

\author{
Z P. Xiong \\ University of Wollongong, zx868@uowmail.edu.au
}

A G. Kostryzhev

University of Wollongong, andrii@uow.edu.au

N E. Stanford

Deakin University

E V. Pereloma

University of Wollongong, elenap@uow.edu.au

Follow this and additional works at: https://ro.uow.edu.au/eispapers

Part of the Engineering Commons, and the Science and Technology Studies Commons

Research Online is the open access institutional repository for the University of Wollongong. For further information contact the UOW Library: research-pubs@uow.edu.au 


\title{
Microstructures and mechanical properties of dual phase steel produced by laboratory simulated strip casting
}

\author{
Abstract \\ Conventional dual phase (DP) steel (0.08C-0.81Si-1.47Mn-0.03Al wt.\%) was manufactured using \\ simulated strip casting schedule in laboratory. The average grain size of prior austenite was 117. \pm .44. \\ $\mu \mathrm{m}$. The continuous cooling transformation diagram was obtained. The microstructures having polygonal \\ ferrite in the range of $40-90 \%$, martensite with small amount of bainite and Widmanstätten ferrite were \\ observed, leading to an ultimate tensile strength in the range of 461-623. MPa and a corresponding total \\ elongation in the range of $0.31-0.10$. All samples exhibited three strain hardening stages. The \\ predominant fracture mode of the studied steel was ductile, with the presence of some isolated cleavage \\ facets, the number of which increased with an increase in martensite fraction. Compared to those of hot \\ rolled DP steels, yield strength and ultimate tensile strength are lower due to large ferrite grain size, \\ coarse martensite area and Widmanstätten ferrite.

\section{Disciplines} \\ Engineering | Science and Technology Studies

\section{Publication Details} \\ Xiong, Z. P., Kostryzhev, A. G., Stanford, N. E. \& Pereloma, E. V. (2015). Microstructures and mechanical \\ properties of dual phase steel produced by laboratory simulated strip casting. Materials and Design, 88 \\ 537-549.
}




\title{
Microstructures and Mechanical Properties of Dual Phase Steel produced by Laboratory Simulated Strip Casting
}

\author{
Z.P. Xiong ${ }^{1 *}$, A.G. Kostryzhev ${ }^{1}$, N.E. Stanford ${ }^{3}$, E.V. Pereloma ${ }^{1,2}$ \\ ${ }^{1}$ School of Mechanical, Materials and Mechatronic Engineering, University of \\ Wollongong, Wollongong, NSW 2522, Australia \\ ${ }^{2}$ Electron Microscopy Centre, University of Wollongong, Wollongong, NSW 2519, \\ Australia \\ ${ }^{3}$ Institute of Frontier Materials, Deakin University, Geelong, Victoria 3216, Australia
}

\begin{abstract}
Conventional dual phase (DP) steel (0.08C-0.81Si-1.47Mn-0.03Al wt. \%) was manufactured using simulated strip casting schedule in laboratory. The average grain size of prior austenite was $117 \pm 44 \mu \mathrm{m}$. The continuous cooling transformation diagram was obtained. The microstructures having polygonal ferrite in the range of 40-90\%, martensite with small amount of bainite and Widmanstätten ferrite were observed, leading to an ultimate tensile strength in the range of $461-623 \mathrm{MPa}$ and a corresponding total elongation in the range of $0.31-0.10$. All samples exhibited three strain hardening stages. The predominant fracture mode of the studied steel was ductile, with the presence of some isolated cleavage facets, the number of which increased with an increase in martensite fraction. Compared to those of hot rolled DP steels, yield strength and ultimate tensile strength are lower due to large ferrite grain size, coarse martensite area and Widmanstätten ferrite.
\end{abstract}

Key words: Strip casting; Dual phase steel; Continuous cooling transformation diagram; Mechanical properties; Crussard-Jaoul model; Electron microscopy

*Correspondence author email address: zuileniwota@126.com (Z.P. Xiong) 


\section{Introduction}

Dual phase (DP) steels are widely used in automotive industry due to a good combination of continuous yielding behaviour, high strength, high strain hardening rate, low yield stress-to-tensile strength ratio and good formability [1-3]. DP steels have high tensile strength in the range of $500 \sim 1200 \mathrm{MPa}$ and total elongation in the range of $12 \sim 34 \%$, which depend on fractions of ferrite, martensite and bainite $[1,4]$. Traditional microstructures of DP steels consist of polygonal ferrite and martensite. To satisfy custom requirements, ferrite-bainite-martensite and ferrite-bainite steels were produced in order to modify mechanical properties: bainite instead of martensite were shown to improve formability with a little decrease of strength [5-7]. The effect of martensite fraction, distribution and martensite region size, and the effect of ferrite fraction and grain size on mechanical behaviour of DP steels have been intensively studied. With increasing the martensite fraction, the yield strength and ultimate tensile strength increase while uniform and total elongations decrease $[8,9]$. The distribution of martensite also affects the mechanical behaviour [10-12]. Martensite regions existing as isolated areas within ferrite matrix result in a better combination of strength and ductility than martensite regions forming a chain-like network structure surrounding ferrite [10]. Refinement of ferrite or/and martensite regions simultaneously enhances strength and ductility [13-16]. Ultrafine-grained DP steels with the average ferrite grain size of $\sim 1.2 \mu \mathrm{m}$ exhibit a high ultimate tensile strength up to $1000 \mathrm{MPa}[13]$.

In industry, the DP steels are successfully produced using hot rolling and cold rolling \& annealing [1]. As alternative, the strip casting could be suggested as a more economic and environmentally friendly way for DP steels production. This technology is already used for carbon steels, silicon steels and stainless steels in industry $[17,18]$. It allows obtaining several millimetres thick strips directly from molten metals [17, 18]. Due to this and elimination of many subsequent hot rolling stages required by conventional continuous casting and thin slab casting, the strip casting process has many advantages, such as energy saving and emission reduction, lower capital and operating costs, a smaller and more flexible operating regime, a higher tolerance to a high residual scrap and easy adjustment for different steel grades [17-20].

In this study, the feasibility of producing DP steel using strip casting was investigated in the laboratory. Heat treatment schedules were designed to obtain microstructures with $40 \% \sim 90 \%$ ferrite. Mechanical properties were tested and compared to hot rolled DP steels. The correlation between microstructure and mechanical properties was analysed.

\section{Materials and experimental techniques}

The chemical composition of studied DP steel is shown in Table 1. Square specimens of $36 \times 36 \mathrm{~mm}^{2}$ and $1.2 \mathrm{~mm}$ thickness and cylindrical specimens of $20 \mathrm{~mm}$ diameter 
and $6 \mathrm{~mm}$ length were produced via dip tester at Deakin University in order to simulate rapid cooling during solidification in strip casting process [21]. The dip tester is used to immerse a copper substrate into molten steel for a short and controlled period of time to simulate a rapid solidification. As-cast microstructure consisted predominantly of martensite and some bainite as shown in Fig. 1.

Heat treatments were carried out using a Theta Dilatronic III Quenching and Deformation dilatometer. It was operated under a vacuum of $\sim 6.7 \times 10^{-2} \mathrm{~Pa}$ which prevented oxidation and decarburization of the samples. The temperature was measured using an S-type (Pt/Pt-10\%Rh) thermocouple spot-welded to the surface centre of a cylindrical and flat samples (Fig. 2).

To simulate the prior austenite grain size (PAGS) observed in cast samples, the flat samples (Fig. 2b) were heated at a rate of $30 \mathrm{Ks}^{-1}$ to 1250 or $1300{ }^{\circ} \mathrm{C}$, held for 120 or $180 \mathrm{~s}$, and then helium quenched to room temperature at a rate of around $140 \mathrm{Ks}^{-1}$.

To obtain the continuous cooling transformation (CCT) diagram, cylindrical samples (Fig. 2a) were heated at a rate of $30 \mathrm{Ks}^{-1}$ to $1300{ }^{\circ} \mathrm{C}$, held for $180 \mathrm{~s}$ to simulate the grain size and distribution of prior austenite in strip casting, and then cooled to room temperate at cooling rates of $0.1,1,3,10,40$ and $90 \mathrm{Ks}^{-1}$.

The schedule to simulate strip casting process is illustrated in Fig. 3.a. The samples were heated at a rate of $30 \mathrm{Ks}^{-1}$ to the austenitisation temperature $\mathrm{T}_{\mathrm{A}}=1300{ }^{\circ} \mathrm{C}$, held for time $t_{A}=180 \mathrm{~s}$, cooled to the austenite-to-ferrite transformation region at a rate of $90 \mathrm{Ks}^{-1}$ or cooled to $1000{ }^{\circ} \mathrm{C}$ at a rate of $30 \mathrm{Ks}^{-1}$ and then cooled at a rate of $10 \mathrm{Ks}^{-1}$ (hereafter referred as $30-10 \mathrm{Ks}^{-1}$ schedule) to ferrite formation temperature $\mathrm{T}_{\mathrm{F}}$, held for $t_{F}$ time to achieve the desired ferrite fraction, and then quenched to the room temperature at $140 \mathrm{Ks}^{-1}$ using helium.

Following the heat treatments, the specimens were cross-cut in the centre perpendicular to the long axis. The centre area of the cross section was used for observation. To reveal the prior austenite grain boundaries, the specimens were etched for $15 \sim 20 \mathrm{~s}$ at $65{ }^{\circ} \mathrm{C}$ temperature in the solution of saturated picric acid in ethanol plus few drops of benzene sulfonate. Equivalent grain diameter was utilised to describe the distribution of prior austenite grain sizes. Approximately $150 \sim 250$ grains were measured for each condition. Etching with 2 vol.\% nital was used to reveal ferrite and martensite. Microstructures and fracture surfaces were studied using a Leica DMR research optical microscope (OM), a JEOL JSM-7001F field emission gun - scanning electron microscope (FEG - SEM) operating at $15 \mathrm{kV}$ of accelerating voltage and fitted with an $80 \mathrm{~mm}^{2} \mathrm{X}$-Max energy dispersive X-ray spectroscopy (EDS) detector, and a JEOL 2011 transmission electron microscope (TEM) operating at 200 $\mathrm{kV}$. Thin foils for TEM were prepared using twin jet electropolishing method with an electrolyte containing $10 \%$ of perchloric acid and methanol. The volume fraction of retained austenite was measured using the X-ray diffraction (XRD) technique. XRD 
was conducted for a scattering angle $2 \theta=38-150^{\circ}$ on the surface of flat samples (Fig. $2 b$ ) after electropolishing. Fractions of phases were calculated based on pixel quantities of different grey scales using Image Pro-Plus and Photoshop software. The equivalent circle diameter was calculated using at least 260 ferrite grains or martensite regions.

Tensile testing employed sub-sized specimens (Fig. 3.b) and an in-house modified "Kammrath and Weiss GmbH" tensile stage with $5 \mathrm{kN}$ load cell. The thickness of tensile test samples was between 0.8 and $1.0 \mathrm{~mm}$. Tensile tests were carried out on a minimum of two dog-bone samples per condition at an initial strain rate of $4 \times 10^{-4} \mathrm{~s}^{-1}$. The strain hardening rate $(\theta)$ and strain hardening exponent $(n)$ were calculated as follows,

$$
\begin{aligned}
& \theta=d \sigma / d \varepsilon \\
& n=d(\ln \sigma) / d(\ln \varepsilon)
\end{aligned}
$$

where $\sigma$ is true stress and $\varepsilon$ is true strain [22].

\section{Results}

\subsection{Prior austenite microstructure simulation}

Fig. 4 shows typical prior austenite grain structures in as-cast and heat treated samples. PAGS distributions after different austenitisation schedules are shown in Fig. 5. PAGS increased with an increase in holding time or holding temperature: after holding at $1250{ }^{\circ} \mathrm{C}$ for 120 and $180 \mathrm{~s}$, the average grain size was $48 \pm 19$ and $83 \pm 37 \mu \mathrm{m}$ respectively; while after holding at $1300{ }^{\circ} \mathrm{C}$ for 120 and $180 \mathrm{~s}$, the average grain size was $72 \pm 30$ and $117 \pm 44 \mu \mathrm{m}$ respectively. The average grain size after holding at $1300{ }^{\circ} \mathrm{C}$ for $180 \mathrm{~s}(117 \pm 44 \mu \mathrm{m})$ was very close to that of as-cast sample $(118 \pm 57 \mu \mathrm{m})$. In addition, the sample held at $1300{ }^{\circ} \mathrm{C}$ for $180 \mathrm{~s}$ had comparable prior austenite grain size distribution to that of as-cast sample (c.f. Fig. 5a and e). Therefore, this condition was selected for all future experiments.

\subsection{Continuous cooling transformation diagram}

The CCT diagram is plotted in Fig. 6 while the corresponding microstructures are shown in Fig. 7. Ferrite and pearlite formed at the cooling rate of $0.3 \mathrm{Ks}^{-1}$. When the cooling rate was increased to $1 \mathrm{Ks}^{-1}$, bainite started to form. A small amount of pearlite was still observed at $3 \mathrm{Ks}^{-1}$. With cooling rate increasing to 10 and $40 \mathrm{Ks}^{-1}$, more bainite formed and a very little fraction of allotriomorphic ferrite was found at prior austenite grain boundaries. When cooling rate reached $90 \mathrm{Ks}^{-1}$, the microstructure was fully bainite and martensite. At $90 \mathrm{Ks}^{-1}$ the bainite transformation start temperature (Bs) was determined to be $644{ }^{\circ} \mathrm{C}$, whereas martensite started to form at $\mathrm{Ms}=426{ }^{\circ} \mathrm{C}$. As expected [23], austenite to ferrite transformation start $\left(\mathrm{A}_{\mathrm{r} 1}\right)$ and finish $\left(\mathrm{A}_{\mathrm{r} 3}\right)$ temperatures tended to decrease with increasing cooling rate. However, the bainite start transformation temperature at first decreased with an increase in cooling rate up to $3 \mathrm{Ks}^{-1}$ from 468 to $398{ }^{\circ} \mathrm{C}$, and then increased with 
further increasing cooling rate up to $90 \mathrm{Ks}^{-1}$, which corresponds to observations by other researchers $[24,25]$.

3.3 Effect of holding temperature, holding time and cooling rate on austenite to ferrite transformation

Based on the CCT diagram, four holding temperatures of $600,650,670$ and $700{ }^{\circ} \mathrm{C}$ were chosen to investigate ferrite formation. For the cooling rate of $90 \mathrm{Ks}^{-1}$ from austenitisation temperature to ferrite formation temperature, the Time-Temperature-Transformation (TTT) diagram is illustrated in Fig. 8a. As seen from this diagram, holding at $650{ }^{\circ} \mathrm{C}$ required a minimum time to start ferrite formation. Therefore, the temperature of $650{ }^{\circ} \mathrm{C}$ was selected for investigation of the effect of time on ferrite formation.

A dependence of ferrite fraction on holding time for two cooling rates is plotted in Fig. 8 b. For the cooling rate of $90 \mathrm{Ks}^{-1}$, the ferrite formation was fast within the first $100 \mathrm{~s}$ of holding. Then, the formation of ferrite continued at a slower rate until reaching $81 \pm 2 \%$, the value corresponding to that defined by the lever rule. For the cooling schedule of $30-10 \mathrm{Ks}^{-1}$, ferrite formed during cooling from 1300 to $650{ }^{\circ} \mathrm{C}$, as evident by the presence of $20 \pm 6 \%$ ferrite in the sample immediately quenched on reaching $650{ }^{\circ} \mathrm{C}$. Cooling with $30-10 \mathrm{Ks}^{-1}$ schedule resulted in a higher ferrite fraction for the same holding time (Fig. 8b), compared to the cooling at $90 \mathrm{Ks}^{-1}$. In addition, cooling with $30-10 \mathrm{Ks}^{-1}$ schedule better depicts the industrial ones [20, 21]. Thus, the microstructures and mechanical properties were characterised only for the samples with the cooling rate of $30-10 \mathrm{Ks}^{-1}$ in the following sections.

\subsection{Microstructure characterisation}

Microstructures of samples cooled at $30-10 \mathrm{Ks}^{-1}$ and held at $650{ }^{\circ} \mathrm{C}$ for different times are shown in Figs. 9, 10 and 11. The ferrite fractions of $0.42 \pm 0.06,0.64 \pm 0.05$, $0.78 \pm 0.01$ and $0.85 \pm 0.03$ were obtained after holding for $30,40,50$ and $60 \mathrm{~s}$, respectively (Fig. 9). Hereafter, these samples were denoted as DP 30, DP 40, DP 50 and DP 60, respectively. The microstructures for all holding times consisted of polygonal ferrite, martensite, and very little amounts of bainite and Widmänstatten ferrite (Figs. 10 and 11). The XRD measurements showed the absence of face-centred cubic phases (Fig. 12). This suggests the absence of retained austenite or its amount below the detection level by XRD. In addition, martensite regions (indicated by arrows in Fig. 10c and d) exhibited concave and convex shape. As an example, the details of microstructure for DP 40 condition are shown in Fig. 11. Optical microstructure (Fig. 11 a) shows a general view of microstructure, containing $64 \pm 5 \%$ polygonal ferrite and Widmänstatten ferrite with martensite regions. A small amount of bainite was found in martensite regions using SEM (Fig. 11b). A general view of martensite packets in regions surrounded by polygonal ferrite is seen in bright field TEM image in Fig. 11c. Equaixed polygonal ferrite grains with a low dislocation 
density are visible in Fig. 11d. Lath martensite with high dislocation density, which formed packets, is shown in Fig. 11e. Unfortunately, Widmänstatten ferrite and bainite were not found using TEM because of their low density.

Grain sizes of ferrite and sizes of martensite regions are given in Table 2 while their representative distributions are plotted in Fig. 13. The average grain size of ferrite was around $20 \mu \mathrm{m}$ while the average size of martensite regions was around $15 \mu \mathrm{m}$. The microstructure was inhomogeneous, i.e. a large size difference of one to two orders of magnitude between the largest and smallest grains was observed. DP 40, DP 50 and DP 60 had a log-normal grain size distribution of ferrite (Fig. 13c shows a representative distribution) while DP 30 exhibited an exponential grain size distribution of ferrite (Fig. 13a). All of the samples had an exponential size distribution of martensite regions (representative distributions are shown in Figs. 13b and d). Polygonal ferrite nucleated at prior austenite grain boundaries. As holding time increased, polygonal ferrite grains grew, resulting in larger grain size (c.f. Fig. 13a and c). Meanwhile, prior austenite was consumed, leading to smaller size of martensite regions after quenching (c.f. Fig. 13b and d).

\subsection{Mechanical properties}

Typical round-house engineering stress-strain curves inherent in DP steels [10, 26] were also observed in our steel for all four heat treatment conditions (Fig. 14a). With a decrease in ferrite fraction from 0.85 to 0.42 the yield strength (YS) and ultimate tensile strength (UTS) increased from 290 to $381 \mathrm{MPa}$ and from 461 to $623 \mathrm{MPa}$, respectively (Table 3 ), while the corresponding uniform elongation and total elongation decreased from 0.17 to 0.063 and from 0.31 to 0.10 , respectively. These types of behaviour correspond to those in hot rolled DP steels $[9,27]$. The product of UTS and total elongation, which can be used to characterise toughness, increased with increasing ferrite fraction (Table 3).

The strain hardening rate decreased with strain following an exponential function (Fig. 14b). With decreasing ferrite fraction, the strain hardening rate increased. The strain hardening exponent for all heat treatment conditions increased steeply at low strains and then saturated (Fig. 14c). However, the behaviour of strain hardening exponent varied with ferrite fraction. A sample having a lower amount of ferrite (larger amount of martensite) showed the maximum of the exponent at lower strains. With further straining, the exponent decreased more quickly for a sample with a lower ferrite fraction. For example, it quickly increased to a maximum value of 0.22 at a true strain of 0.03 and then quickly decreased to 0.12 for DP 40 . DP 60 showed a more gradual increase to a maximum value of 0.20 at a true strain of 0.08 and then a gradual, slightly fluctuated decrease to 0.17 at a true strain of 0.14 .

\subsection{Fractography}


Although the necking behaviour was observed for all four processing conditions, it varied with ferrite fraction. With an increase in ferrite fraction, the fracture surface at low magnification changed from flat to uneven and to conical shape (Fig. 15a1 - d1), and the fracture surface at high magnification showed larger and dipper voids at high magnification, the density of which increased with an increase in ferrite fraction (c.f. Fig. $15 \mathrm{a} 2$ and $\mathrm{d} 2$ ). The sample with $85 \%$ ferrite exhibited a ductile fracture surface characterised by many voids (Fig. 15d2). However, when ferrite fraction increased to 0.42 , the fracture surface consisted of many smaller voids and some larger cleavage facets (Fig. 15a2), indicating the predominant ductile with some brittle fracture. These support the transition to a more ductile behaviour with an increase in ferrite fraction. Besides, in some voids the MnS inclusions were observed for all heat treatment conditions (Fig. 16), which could be a site for void formation $[6,28]$.

\section{Discussion}

\subsection{The effect of ferrite fraction on mechanical behaviour}

In the studied steel YS increased with a decrease in ferrite fraction (an increase in martensite fraction) due to dislocation density in ferrite increasing with volume change accommodation of martensite formation [29]. There is non-uniform distribution of dislocations within ferrite grains: low density within the grains (Fig. 17a); medium density in the regions adjacent to ferrite-ferrite boundaries (Fig. 17b); high density in the regions adjacent to martensite due to accommodation of volume change during austenite to martensite transformation (Fig. 17 c) [29]. As ferrite fraction increases, there are fewer regions adjacent to martensite. Thus, the overall density of dislocations in ferrite is lower. It results in lower yield strength because when the density of dislocations is low, it is easy for existing dislocations to move unobstructed due to less interaction between the dislocations [16]. The generation of new dislocations in the material with a low density of dislocations is also easier, as the material has capacity for energy storage [14]. During the tensile test, more dislocations piled up near ferrite-martensite interfaces. With increasing ferrite fraction, ferrite-martensite interfaces decreased, leading to a lower YS. This also was observed in Ref [9]. Furthermore, with decrease in the fraction of martensite regions the overall strength of the material is reduced according to the low of mixtures [28].

The initial strain hardening rate and initial strain hardening exponent increased with a decrease in ferrite fraction (Fig. $14 b$ and c) due to an increased initial density of dislocations leading to an earlier dislocation immobilisation and pile-up [9, 16, 26]. The samples with a larger ferrite fraction had a more gradual increase and then a slower decrease in strain hardening exponent. The samples with a lower ferrite fraction exhibited a sharp increase in the strain hardening exponent during early stages of straining, which could be explained by the more rapid increase in the number of dislocations in ferrite. Higher dislocation density in ferrite would result in a reduced mean free path for dislocation movement and a higher dislocation generation rate leading to an earlier increase in the strain hardening exponent. Finally, this led to 
a decreased elongation to failure in samples with lower ferrite fraction. Due to a higher amount of soft phase, the samples with a higher ferrite fraction exhibited more ductile fracture behaviour.

To analyse the multistage strain hardening behaviour in the studied steel the modified Crussard-Jaoul (C-J) model was used [30]:

$\varepsilon=\varepsilon_{0}+c \sigma^{m}$

where $\varepsilon_{0}$ is the initial true strain, $c$ is a constant and $m$ is the strain hardening index. $m$ can be calculated using the following equation:

$\ln (d \sigma / d \varepsilon)=(1-m) \ln \sigma-\ln (\mathrm{cm})$

The plots of $\ln (d \sigma / d \varepsilon)$ versus $\ln \sigma$ are shown in Fig. 14d. The strain hardening behaviour showed three stages, which is a typical phenomenon for DP steels $[5,16$, 26]. As the modified C-J analysis was unable to fit the flow curve over the entire uniform strain range region, values of strain hardening index $m$ for each strain hardening stage are listed in Table 4. A smaller strain hardening index $m$ means higher strain hardening ability. The rate of dislocation accumulation is strongly linked to the ferrite grain size. In this regard, the finer ferrite grain size the smaller is $m_{l}$. As could be seen from Table 4, DP 40 and DP 50 samples with the lowest average grain sizes (Table 2) display the lowest $m_{1}$ values. During Stage 1 coarse ferrite grains deformed preferentially because smaller ferrite grains withstood the lower strain [31]. A small fraction of coarse ferrite grains did exist as shown in Figs. 9, 13a and 13c. During Stage 2, ferrite grains were further strain hardened and restrained by martensite with dislocations piling up in the regions adjacent to martensite, resulting in a lower value of $m_{2}$ than $m_{1}$ for the DP 50 and DP 60 samples, which have high ferrite fractions. On the other hand, the $m_{2}>m_{1}$ value for DP 30 and DP 40 conditions, as higher $m$-values are associated with the larger martensite fraction $[5,16]$. In addition, Widmänstatten ferrite may contribute to deformation in this stage. During Stage 3 the simultaneous deformation of strain hardened ferrite and martensite took place, leading to a continuous decrease in strain hardening rate and higher $m_{3}$-values compared to $m_{1}$ and $m_{2}$. For all conditions, $m_{l}$ is around 5.0 when ferrite fraction is in the range of 0.64 to 0.85 . As ferrite fraction decreased to $0.42, m_{1}$ increased to 6.4 . It is probably because higher martensite fraction affected almost all ferrite grains and induced much more dislocations in ferrite induced by martensite formation [26, 29, 32], resulting in a decrease in strain hardening ability. $m_{2}$ increased with a decrease in ferrite fraction, due to a higher restraint from deformation of ferrite grains by martensite regions, which led to a decrease in strain hardening ability. $m_{3}$ increased with an increase in martensite fraction because martensite has less ability to strain harden due to a very high initial dislocation density and the ferrite is already more strain hardened when the amount of martensite is higher. The value of $m$ calculated using the experimental data for entire strain hardening region increased with decreasing ferrite fraction, which qualitatively corresponds to the discussed above increase in $m_{2}$ and $m_{3}$ and also 
to an increase in strain hardening exponent (Fig. 14c).

\subsection{Comparison with mechanical properties of hot rolled DP steels}

Fig. 18 compares the mechanical properties of the present samples with DP steels that have been conventionally processed. It can be seen that the UTS and YS of the studied DP steel are lower than those of hot rolled ones, while the total elongation is relatively higher $[2,10,13,27,33-39]$. The product of UTS $\times$ total elongation is relatively lower than that of hot rolled ones, which suggests a lower toughness in the studied steel compared to the reference steels. According to the microstructure observation (Figs. 9, 10, 11 and 17) and metallographic analysis (Figs. 13 and Table 2), ferrite grain size and its distribution, size and shape of martensite regions, and presence of Widmänstatten ferrite could be responsible for the lower combination of mechanical properties.

A very coarse prior austenite grain size of $117 \pm 44 \mu \mathrm{m}$ resulted in a large grain size of ferrite due to a small number of ferrite nucleation sites. It is detrimental to YS, UTS and toughness. Based on the Hall - Petch equation $\left(\sigma=\sigma_{0}+k d^{-1 / 2}\right.$, where $\sigma_{0}$ is lattice friction stress, $k$ is constant, $d$ is average grain size and $\sigma$ is YS), YS and UTS decrease with increasing grain size [14]. For example, with an increase in ferrite grain size from 1.2 to $12.4 \mu \mathrm{m}$ when the ferrite fraction was 0.7 , YS and UTS decreased by 80 and $167 \mathrm{MPa}$, respectively [13]. The studied here DP steel had the ferrite grain size of around $20 \mu \mathrm{m}$ (Table 2), which reflected in significantly reduced strength. The size of martensite regions also affects the strength [16]. Large size of martensite regions is harmful to mechanical properties, due to a decrease in geometrically necessary dislocations and effective barriers to dislocation motion in ferrite [16, 40-42]. In addition, the size distribution of martensite regions was not homogeneous, as shown in Figs. 9, 13b and d. Some martensite regions exceeding $50 \mu \mathrm{m}$ (Table 2 and Fig. 13) could reduce ductility, because a coarser martensite may crack at lower strains following stress accumulation $[31,40]$.

In studied steel the ferrite grains were mostly of a polygonal shape while martensite regions exhibited less regular shape and had some concave and convex profiles as indicated by the arrows in Figs. 10c and d. Such shapes of martensite regions can be explained by a variation in the rates of growing polygonal ferrite from prior austenite boundaries. As demonstrated using in situ tensile test in Ref [43], concave and convex parts of martensite regions easily induce stress concentration and plastic deformation localisations, which lead to earlier void formation along the tensile direction and reduce fracture strain.

Widmänstatten ferrite was observed in all four samples as shown in Figs. 10a and b, although it is not common in DP steels. Widmänstatten ferrite can form following polygonal ferrite formation [44]. In our DP steel, a very coarse prior austenite grain size $(117 \pm 44 \mu \mathrm{m})$ led to the large remaining austenite areas after the polygonal ferrite 
formation during holding. This large remaining austenite grains facilitated the formation of Widmänstatten ferrite [45, 46]. Moreover fast cooling following holding at $650{ }^{\circ} \mathrm{C}$ also facilitated the formation of Widmänstatten ferrite [46, 47]. According to Ref [46], Widmänstatten ferrite may increase YS and UTS. However, in the studied DP steel, it also could contribute to the decrease in elongation to failure due to the stress concentration around the tips of Widmänstatten ferrite.

Compared to hot rolling, the studied processing route here did not carry out deformation. In hot rolling deformation in austenite temperature region or in the two-phase region results in an increase in dislocation density and deformation bands in ferrite, and elongated structure [48], leading to the increase in YS and UTS [49, 50]. In the studied DP steel, the dislocation density in ferrite was low (Fig. $17 \mathrm{a}$ and b). On the other hand, deformation facilitates the nucleation and growth of polygonal ferrite, leading to a decrease in the amount of Widmänstatten ferrite [51], a decrease in ferrite grain size and the size of martensite regions [37, 52, 53]. All the aspects of microstructure development discussed here will be taken into account in further technology optimisation.

\section{Conclusion}

The characterisation of microstructure and mechanical properties of DP steel produced by the laboratory simulated strip casting leads to the following conclusions:

(1) The developed processing route for simulation of the strip casting in laboratory, resulted in DP steel microstructures containing 40 90 \% polygonal ferrite, martensite and small amounts of bainite and Widmänstatten ferrite.

(2) For DP steel with nominal composition of $0.08 \mathrm{C}-0.81 \mathrm{Si}-1.47 \mathrm{Mn}-0.03 \mathrm{Al}$, wt. $\%$, experimental CCT and TTT diagrams were obtained. The nose temperature of ferrite formation field was determined being around $650{ }^{\circ} \mathrm{C}$. Decreasing the cooling rate from austenitisation temperature to $650{ }^{\circ} \mathrm{C}$ resulted in larger fraction of ferrite formed.

(3) The variation of ferrite fraction in DP steel resulted in an ultimate tensile strength in the range of $461 \sim 623 \mathrm{MPa}$ and a corresponding total elongation in the range of $0.31 \sim 0.10$. The better strain hardening behaviour was displayed by the samples having higher ferrite fraction (such as 0.42 and 0.64 ). The strain hardening behaviour of studied steels was similar to that of hot rolled DP steels and was characterised by three stages according to modified Crussard-Jaoul model.

(5) The predominant fracture mode was ductile, with the presence of some isolated cleavage facets, the amount of which increased with an increase in martensite fraction.

(4) Comparison of mechanical properties of the studied steel with those of hot rolled 
DP steels showed the lower yield stress and ultimate tensile strength, although the comparable elongation in the former one, due to the large ferrite grain size, coarse martensite regions and the presence of Widmänstatten ferrite. The observed differences are associated with the absence of deformation in the utilised processing schedule.

Acknowledgements: This project was supported by the Australian Research Council (DP130101887). The JEOL JSM-7001F FEG-SEM was funded by the Australian Research Council (LE0882613). The authors thank Dr. A.A. Gazder, UOW for modification of tensile stage.

\section{References:}

[1] R. Kuziak, R. Kawalla, S. Waengler, Advanced high strength steels for automotive industry: a review, Arch. Civ. Mech. Eng. 8 (2008) 103-117.

[2] E. Ahmad, T. Manzoor, N. Hussain, N.K. Qazi, Effect of thermomechanical processing on hardenability and tensile fracture of dual-phase steel, Mater. Design 29 (2008) 450-457.

[3] E. Fereiduni, S.S.G. Banadkouki, Reliability/unreliability of mixture rule in a low alloy ferrite-martensite dual phase steel, J. Alloy Compd. 577 (2013) 351-359.

[4] M. Dziedzic, S. Turczyn, Experimental and numerical investigation of strip rolling from dual phase steel, Arch. Civ. Mech. Eng. 10 (2010) 21-30.

[5] A. Kumar, S.B. Singh, K.K. Ray, Influence of bainite/martensite-content on the tensile properties of low carbon dual-phase steels, Mater. Sci. Eng. A 474 (2008) 270-282.

[6] N. Saeidi, A. Ekrami, Comparison of mechanical properties of martensite/ferrite and bainite/ferrite dual phase 4340 steels, Mater. Sci. Eng. A 523 (2009) 125-129.

[7] A. Ramazani, P.T. Pinard, S. Richter, A. Schwedt, U. Prahl, Characterisation of microstructure and modelling of flow behaviour of bainite-aided dual-phase steel, Comp. Mater .Sci. 80 (2013) 134-141.

[8] M.R. Akbarpour, A. Ekrami, Effect of ferrite volume fraction on work hardening behavior of high bainite dual phase (DP) steels, Mater. Sci. Eng. A 477 (2008) 306-310.

[9] M. Asadi, B.C. De Cooman, H. Palkowski, Influence of martensite volume fraction and cooling rate on the properties of thermomechanically processed dual phase steel, Mater. Sci. Eng. A 538 (2012) $42-52$.

[10] K. Park, M. Nishiyama, N. Nakada, T. Tsuchiyama, S. Takaki, Effect of the martensite distribution on the strain hardening and ductile fracture behaviors in dual-phase steel, Mater. Sci. Eng. A 604 (2014) $135-141$.

[11] G. Avramovic-Cingara, Y. Ososkov, M.K. Jain, D.S. Wilkinson, Effect of martensite distribution on damage behaviour in DP600 dual phase steels, Mater. Sci. Eng. A 516 (2009) 7-16.

[12] M. Mazinani, W.J. Poole, Effect of martensite plasticity on the deformation behavior of a low-carbon dual-phase steel, Metall. and Mater. Trans. A 38 (2007) 328-339.

[13] M. Calcagnotto, Y. Adachi, D. Ponge, D. Raabe, Deformation and fracture mechanisms in fineand ultrafine-grained ferrite/martensite dual-phase steels and the effect of aging, Acta Mater. 59 (2011) 658-670.

[14] P.H. Chang, A.G. Preban, The effect of ferrite grain-size and martensite volume fraction on the tensile properties of dual phase dteel, Acta Metall. Mater. 33 (1985) 897-903.

[15] M. Calcagnotto, D. Ponge, D. Raabe, Effect of grain refinement to $1 \mu \mathrm{m}$ on strength and toughness 
of dual-phase steels, Mater. Sci. Eng. A 527 (2010) 7832-7840..

[16] Z. Jiang, Z. Guan, J. Lian, Effects of microstructural variables on the deformation behaviour of dual-phase steel, Mater. Sci. Eng. A 190 (1995) 55-64.

[17] S. Ge, M. Isac, R.I.L. Guthrie, Progress of strip casting technology for steel; Historical developments ISIJ Int. 52 (2012) 2109-2122.

[18] N. Zapuskalov, Comparison of continuous strip casting with conventional technology, ISIJ Int. 43 (2003) 1115-1127.

[19] R. Wechsler, The status of twin-roll casting technology, Scand. J. Metall. 32 (2003) 58-63.

[20] S. Ge, M. Isac, R.I.L. Guthrie, Progress in strip casting technologies for steel; Technical developments, ISIJ Int. 53 (2013) 729-742.

[21] L. Strezov, J. Herbertson, G.R. Belton, Mechanisms of initial melt/substrate heat transfer pertinent to strip casting, Metall. Mater. Trans. A 31B (2000) 1023-1030.

[22] I.B. Timokhina, P.D. Hodgson, E.V. Pereloma, Transmission electron microscopy characterization of the bake-hardening behavior of transformation-induced plasticity and dual-phase steels, Metall. Mater. Trans. A 38 (2007) 2442-2454.

[23] M. Olasolo, P. Uranga, J.M. Rodriguez-Ibabe, B. Lopez, Effect of austenite microstructure and cooling rate on transformation characteristics in a low carbon $\mathrm{Nb}-\mathrm{V}$ microalloyed steel, Mater. Sci. Eng. A 528 (2011) 2559-2569.

[24] V. Colla, M. Desanctis, A. Dimatteo, G. Lovicu, R. Valentini, Prediction of continuous cooling transformation diagrams for dual-phase steels from the intercritical region, Metall. Mater. Trans. A 42A (2011) 2781-2793.

[25] N. Fonstein, O. Yakubovsky, D. Bhattacharya, F. Siciliano, Effect of niobium on the phase transformation behavior of aluminum containing steels for TRIP products, Mater. Sci. Forum 500-501 (2005) 453-460.

[26] Z.Z. Zhao, T.T. Tong, J.H. Liang, H.X. Yin, A.M. Zhao, D. Tang, Microstructure, mechanical properties and fracture behavior of ultra-high strength dual-phase steel, Mater. Sci. Eng. A 618 (2014) $182-188$

[27] W. Tan, B. Han, S.Z. Wang, Y. Yang, C. Zhang, Y.K. Zhang, Effects of TMCP parameters on microstructure and mechanical properties of hot rolled economical dual phase steel in CSP, J. Iron Steel Res. Int. 19 (2012) 37-41.

[28] Y. Mazaheri, A. Kermanpur, A. Najafizadeh, A novel route for development of ultrahigh strength dual phase steels, Mater Sci. Eng. A 619 (2014) 1-11.

[29] M. Calcagnotto, D. Ponge, E. Demir, D. Raabe, Orientation gradients and geometrically necessary dislocations in ultrafine grained dual-phase steels studied by 2D and 3D EBSD, Mater. Sci. Eng. A 527 (2010) 2738-2746.

[30] Y. Tomita, K. Okabayashi, Tensile stress-strain analysis of cold-worked metals and steels and dual-phase steels, Metall. Trans. A, 16 (1985) 865-872.

[31] F. Al-Abbasi, J. Nemes, Micromechanical modeling of the effect of particle size difference in dual phase steels, Int. J. Solids Struct. 40 (2003) 3379-3391.

[32] A. Karmakar, S. Sivaprasad, S. Kundu, D. Chakrabarti, Tensile behavior of ferrite-carbide and ferrite-martensite steels with different ferrite grain structures, Metall. Mater. Trans. A 45A (2014) 1659-1664.

[33] P. Deb, M.C. Chaturvedi, Influence of thermomechanical treatment on the structure property relationship of a microalloyed dual-phase high-strength, low-alloy ateel, Mater. Sci. Eng. 78 (1986) 
L7-L13.

[34] J. Hu, L.X. Du, J.J. Wang, C.R. Gao, T.Z. Yang, A.Y. Wang, R.D.K. Misra, Microstructures and mechanical properties of a new as-hot-rolled high-strength DP steel subjected to different cooling schedules, Metall. Mater. Trans. A 44A (2013) 4937-4947.

[35] N.G. Kolbasnikov, Y.A. Bezobrazov, A.A. Naumov, Structural evolution of high-strength dual-phase steel in hot rolling, Steel Transl. 43 (2013) 455-459.

[36] J. Lis, A.K. Lis, C. Kolan, Processing and properties of C-Mn steel with dual-phase microstructure, J. Mater. Process Tech. 162 (2005) 350-354.

[37] A.K. Panda, P.K. Ray, R.I. Ganguly, Effect of thermomechanical treatment parameters on mechanical properties of duplex ferrite-martensite structure in dual phase steel, Mater. Sci. Tech. 16 (2000) 648-656.

[38] X.J. Xu, J.Q. Kong, J.P. Lin, R.R. Zheng, Study on a Rolling Process for obtaining ferrite-martensitic (DP) microstructures in ER70S-6 steel, Rev. Adv. Mater. Sci. 33 (2013) 348-353.

[39] R. González, J. García, L. Verdeja, M. Quintana, J. Verdeja, Mechanical behaviour of thermomechanically produced ultrafine grained dual-phase steels, Can. Metall. Quart. 53 (2014) 100-106.

[40] M. Erdogan, S. Tekeli, The effect of martensite particle size on tensile fracture of surface-carburised AISI 8620 steel with dual phase core microstructure, Mater. Design 23 (2002) 597-604.

[41] M. Erdogan, S. Tekeli, The effect of martensite volume fraction and particle size on the tensile properties of a surface-carburized AISI 8620 steel with a dual-phase core microstructure, Mater. Charact. 49 (2002) 445-454.

[42] K. Kocatepe, M. Cerah, M. Erdogan, Effect of martensite volume fraction and its morphology on the tensile properties of ferritic ductile iron with dual matrix structures, J. Mater. Process. Tech. 178 (2006) 44-51.

[43] M. Azuma, S. Goutianos, N. Hansen, G. Winther, X. Huang, Effect of hardness of martensite and ferrite on void formation in dual phase steel, Mater. Sci. Tech. 28 (2012) 1092-1100.

[44] S.F. Di Martino, G. Thewlis, Transformation characteristics of ferrite/carbide aggregate in continuously cooled, low carbon-manganese steels, Metall. Mater. Trans. A 45 (2014) 579-594.

[45] R.L. Bodnar, S.S. Hansen, Effects of austenite grain size and cooling rate on Widmanstätten ferrite formation in low-alloy steels, Metall. Mater. Trans. A 25 (1994) 665-675.

[46] R.L. Bodnar, S.S. Hansen, Effects of Widmanstätten ferrite on the mechanical properties of a 0.2 pct C-0.7 pct Mn steel, Metall. Mater. Trans. A 25 (1994) 763-773.

[47] S.I. Kim, Y. Lee, Influence of cooling rate and boron content on the microstructure and mechanical properties of hot-rolled high strength interstitial-free steels, Met. Mater. Int. 18 (2012) 735-744.

[48] N.M. Xiao, M.M. Tong, Y.J. Lan, D.Z. Li, Y.Y. Li, Coupled simulation of the influence of austenite deformation on the subsequent isothermal austenite-ferrite transformation, Acta Mater. 54 (2006) 1265-1278.

[49] K. Nakashima, M. Suzuki, Y. Futamura, T. Tsuchiyama, S. Takaki, Limit of dislocation density and dislocation strengthening in iron, Mater. Sci. Forum 503-504 (2006) 627-632..

[50] M.D. Taylor, K.S. Choi, X. Sun, D.K. Matlock, C.E. Packard, L. Xu, E. Barlat, Correlations between nanoindentation hardness and macroscopic mechanical properties in DP980 steels, Mater. Sci. Eng. A 597 (2014) 431-439.

[51] R.H. Larn, J.R. Yang, The effect of compressive deformation of austenite on the Widmanstätten 
ferrite transformation in Fe-Mn-Si-C steel, Mater Sci. Eng. A 264 (1999) 139-150.

[52] A.R. Salehi, S. Serajzadeh, A.K. Taheri, A study on the microstructural changes in hot rolling of dual-phase steels, J. Mater. Sci. 41 (2006) 1917-1925.

[53] S.C. Hong, K.S. Lee, Influence of deformation induced ferrite transformation on grain refinement of dual phase steel, Mater. Sci. Eng. A 323 (2002) 148-159. 
Figure captions

Fig. 1 The microstructure of DP steel after dip casting.

Fig. 2 (a) Cylindrical samples used for the determination of continuous cooling transformation diagrams, and (b) flat samples used for prior austenite grain size measurement and simulation of strip casting.

Fig. 3 Schematic diagrams of (a) heat treatments to simulate strip casting and (b) tensile test sample.

Fig. 4 Comparison of prior austenite microstructures (a) in as-cast condition and (b) as-quenched after holding at $1300{ }^{\circ} \mathrm{C}$ for $180 \mathrm{~s}$

Fig. 5 Prior austenite grain size distributions in (a) as-cast and (b-e) quenched conditions after holding at (b) $1250{ }^{\circ} \mathrm{C}$ for $120 \mathrm{~s}$, (c) $1250{ }^{\circ} \mathrm{C}$ for $180 \mathrm{~s}$, (d) $1300{ }^{\circ} \mathrm{C}$ for $120 \mathrm{~s}$ and (e) $1300{ }^{\circ} \mathrm{C}$ for $180 \mathrm{~s}$

Fig. 6 Continuous cooling transformation (CCT) diagram of as-cast DP steel cooled from $1300{ }^{\circ} \mathrm{C}$ after holding for $180 \mathrm{~s}$. $F$ is ferrite, $P$ is pearlite, $B$ is bainite and $M$ is martensite

Fig. 7 Microstructures after austenitising for $180 \mathrm{~s}$ at $1300{ }^{\circ} \mathrm{C}$ and cooling to room temperature at cooling rates of (a) 0.3 , (b) 1 , (c) 3, (d) 10 , (e) 40 and (f) $90 \mathrm{Ks}-1 . F$ is ferrite, $P$ is pearlite, $B$ is bainite and $M$ is martensite

Fig. 8 (a) Time-Temperature-Transformation (TTT) diagram and (b) ferrite fraction versus holding time when holding at $650{ }^{\circ} \mathrm{C}$

Fig. 9 Optical microstructures after holding at $650{ }^{\circ} \mathrm{C}$ for (a) $30 \mathrm{~s}$, (b) $40 \mathrm{~s}$, (c) $50 \mathrm{~s}$ and (d) $60 \mathrm{s.} P F$ is polygonal ferrite

Fig. 10 Microstructures of DP 60 characterised using scanning electron microscopy. $P F$ is polygonal ferrite, $W F$ is Widmänstatten ferrite and $M$ is martensite. Arrows in (c, d) point the concave and convex shapes of martensite regions.

Fig. 11 Representative microstructures of DP 40: (a) optical, (b) SEM and (c) TEM images. Higher magnification details of polygonal ferrite and lath martensite are shown in (d) and (e) respectively. $P F$ is polygonal ferrite, $W F$ is Widmänstatten ferrite, $B$ is bainite and $M$ is martensite. The zone axis of inset in (d) is $[001]_{\alpha}$ and of inset in $(\mathrm{c}, \mathrm{e})$ is $[111]_{\alpha}$.

Fig. 12 X-ray diffraction pattern of DP 40 sample 
Fig. 13 The size distributions of $(a, c)$ ferrite grains and $(b, d)$ martensite regions for $(a$, b) DP 30 and (c, d) DP 60.

Fig. 14 (a) Engineering stress-strain curves for all studied conditions, (b) strain hardening rate and (c) instantaneous strain hardening exponent $\mathrm{n}$ as a function of true strain, and (d) strain hardening behaviours based on the modified Crussard-Jaoul model analysis, where three distinct stages of strain hardening were denoted by the vertical lines and numbers.

Fig. 15 The macroscopic $(\mathrm{a} 1-\mathrm{d} 1)$ and microscopic $(\mathrm{a} 2-\mathrm{d} 2)$ fractography of (a) DP 30, (b) DP 40, (c) DP 50 and (d) DP 60. Arrows indicate cleavage facets.

Fig. 16 (a) Selected SEM image showing MnS inclusions in voids and (b) the representative EDS spectrum of MnS in DP 60. Arrows show some inclusions.

Fig. 17 Selected TEM micrographs of dislocation structure for DP 60: (a) in polygonal ferrite far from grain boundaries, (b) in the region near ferrite - ferrite grain boundary, and (c) in ferrite adjacent to martensite and (d) a higher magnification of ferrite shown in (c).

Fig. 18 Comparison of the mechanical properties of studied steels with the properties of hot rolled DP steels [2, 10, 13, 27, 33-39]: (a) yield strength, (b) ultimate tensile strength, (c) total elongation and (d) ultimate tensile strength $\times$ total elongation. 


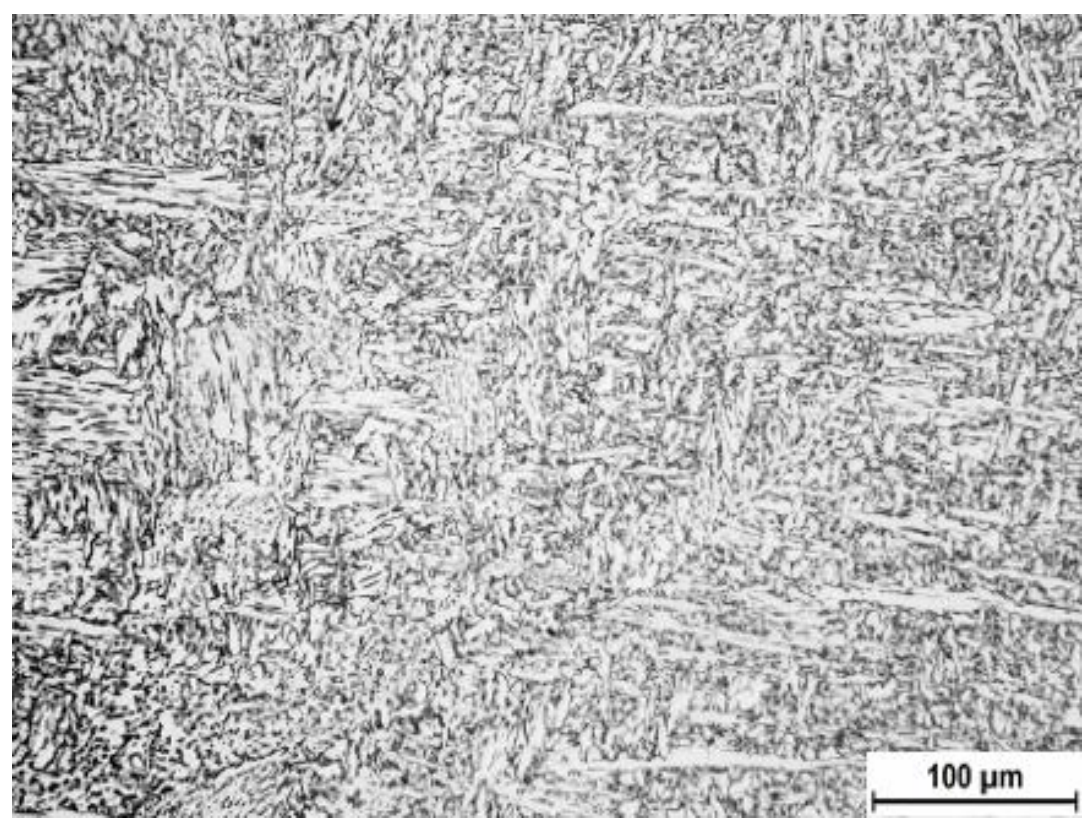

Fig.1 The microstructure of DP steel after dip casting. 

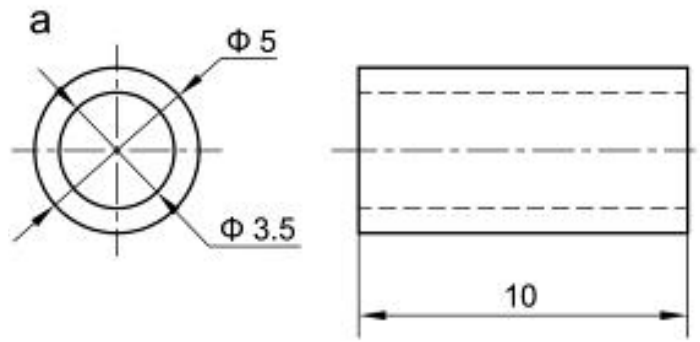

b

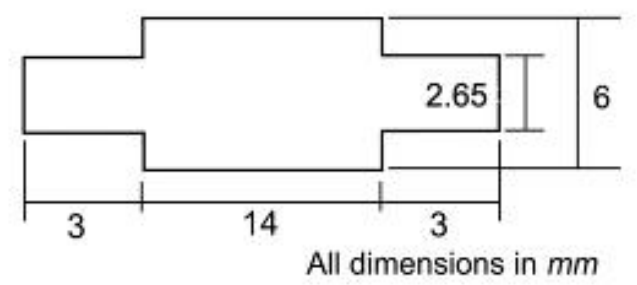

Fig.2 (a) Cylindrical samples used for the determination of continuous cooling transformation diagrams, and (b) flat samples used for prior austenite grain size measurement and simulation of strip casting. 
a

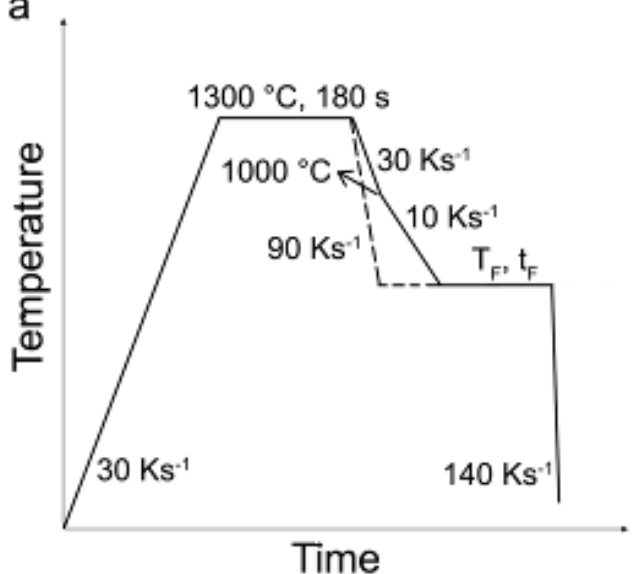

b

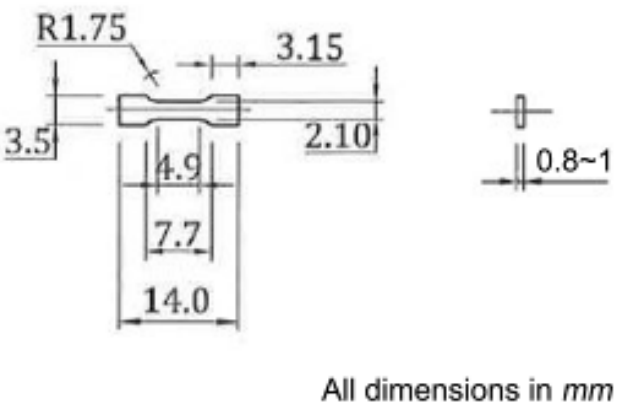

Fig.3 Schematic diagrams of (a) heat treatments to simulate strip casting and (b) tensile test sample. 
a

b

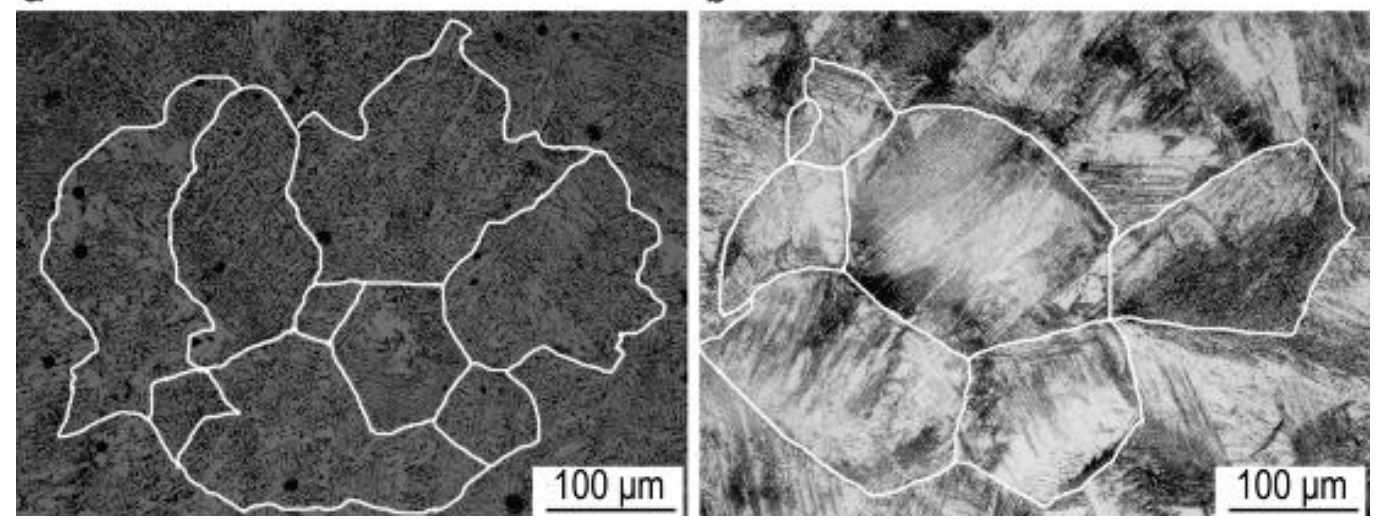

Fig.4 Comparison of prior austenite microstructures (a) in as-cast condition and (b) as-quenched after holding at $1300{ }^{\circ} \mathrm{C}$ for $180 \mathrm{~s}$. 

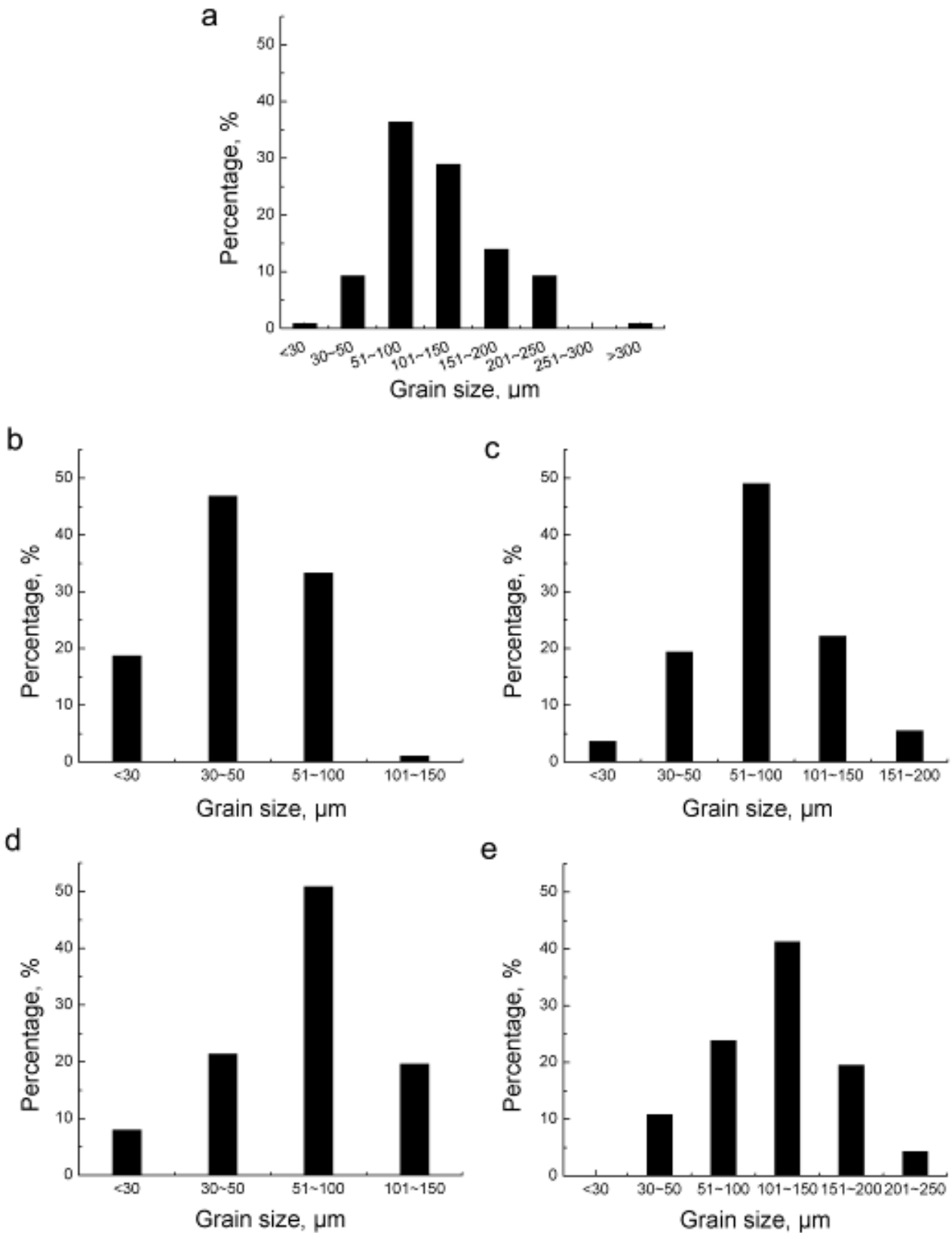

Fig.5 Prior austenite grain size distributions in (a) as-cast and (b-e) quenched conditions after holding at (b) $1250{ }^{\circ} \mathrm{C}$ for $120 \mathrm{~s}$, (c) $1250{ }^{\circ} \mathrm{C}$ for $180 \mathrm{~s}$, (d) $1300{ }^{\circ} \mathrm{C}$ for $120 \mathrm{~s}$ and (e) $1300{ }^{\circ} \mathrm{C}$ for $180 \mathrm{~s}$. 


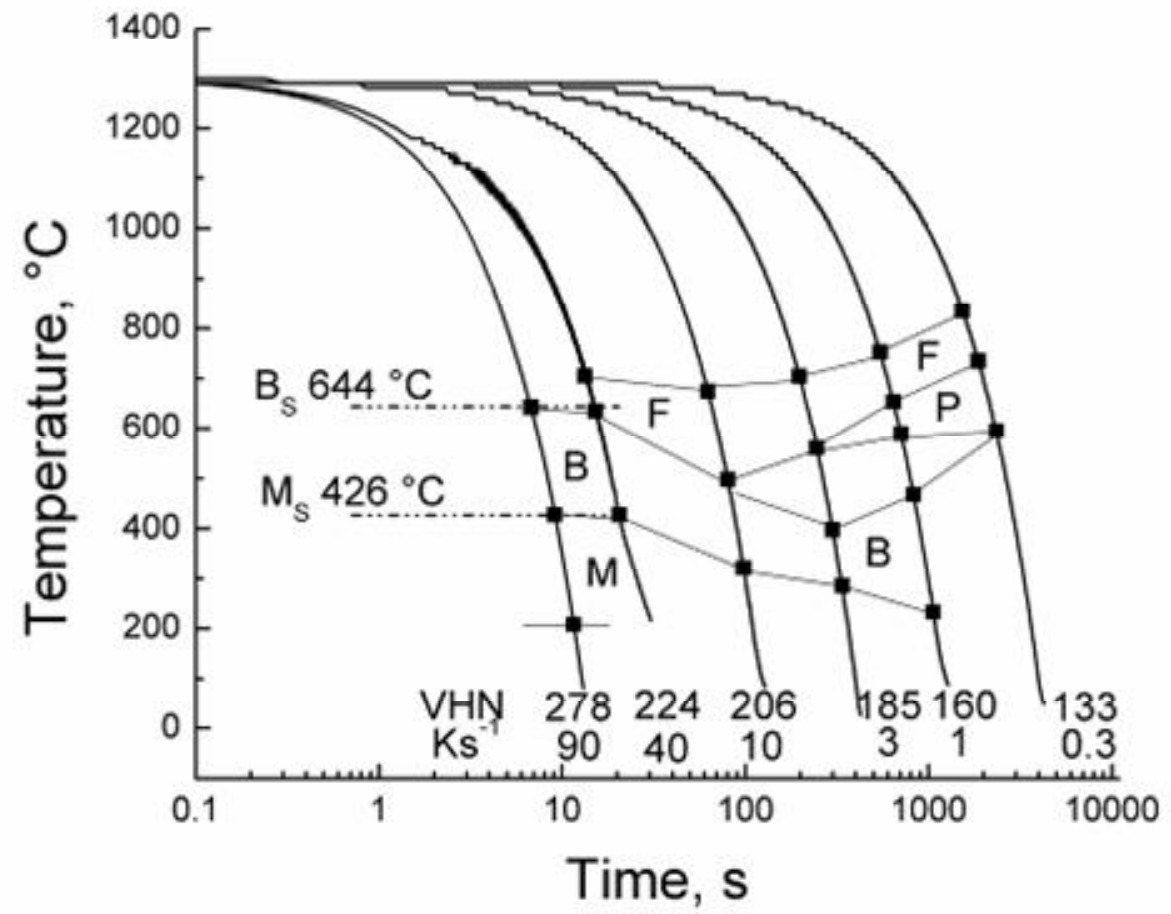

Fig.6 Continuous cooling transformation (CCT) diagram of as-cast DP steel cooled from $1300{ }^{\circ} \mathrm{C}$ after holding for $180 \mathrm{~s} . F$ is ferrite, $P$ is pearlite, $B$ is bainite and $M$ is martensite 

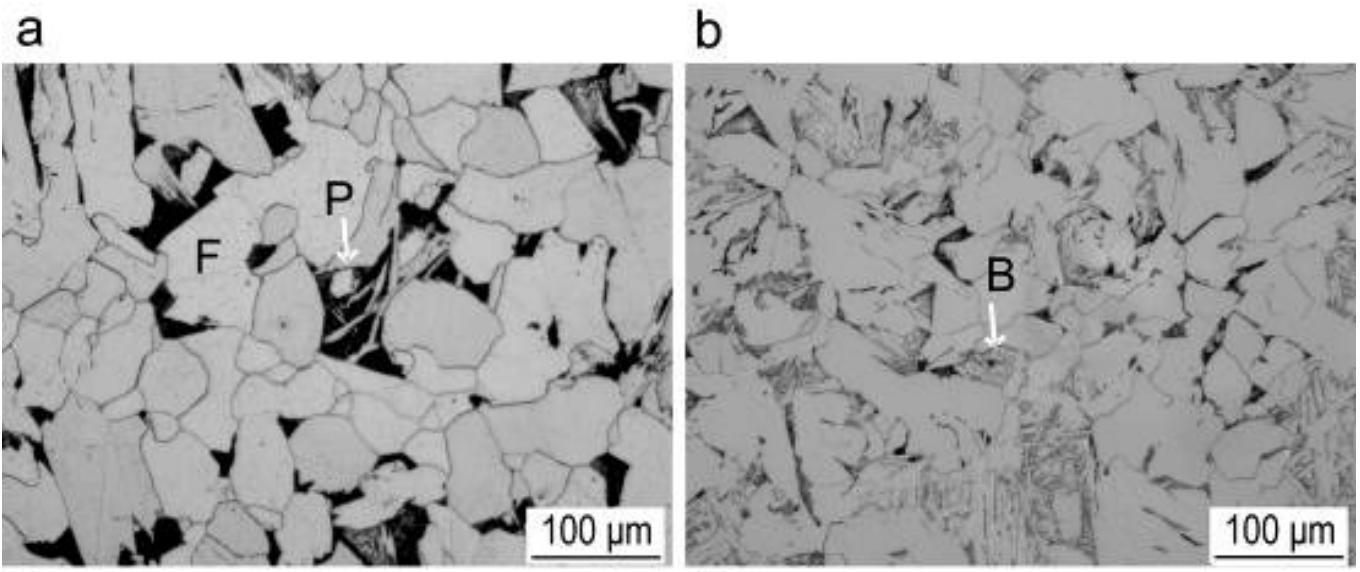

C
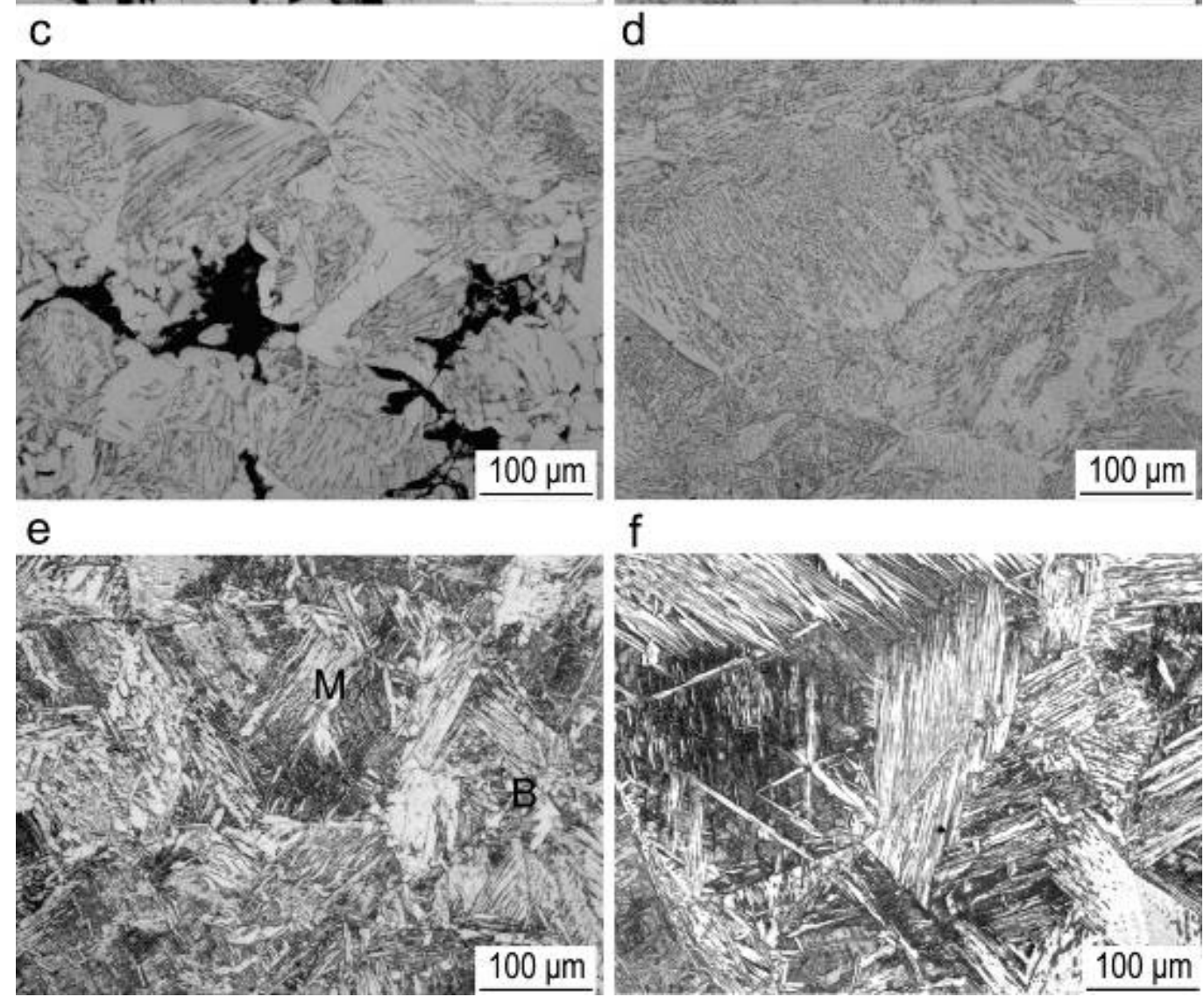

f

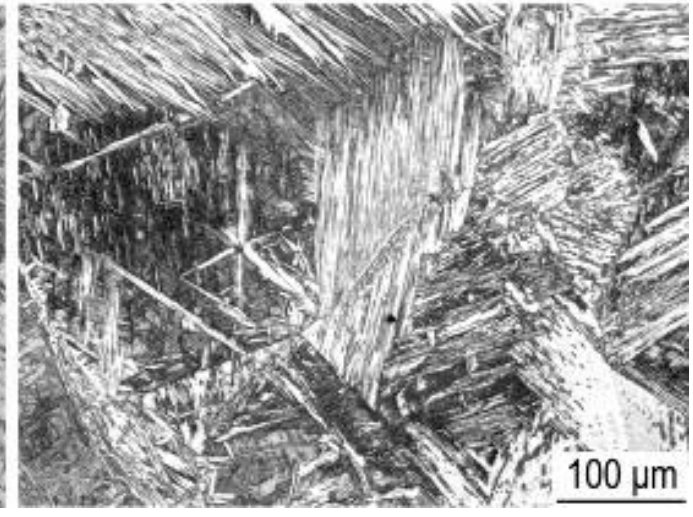

Fig.7 Microstructures after austenitising for $180 \mathrm{~s}$ at $1300{ }^{\circ} \mathrm{C}$ and cooling to room temperature at cooling rates of (a) 0.3 , (b) 1 , (c) 3, (d) 10 , (e) 40 and (f) $90 \mathrm{Ks}^{-1} . F$ is ferrite, $P$ is pearlite, $B$ is bainite and $M$ is martensite 

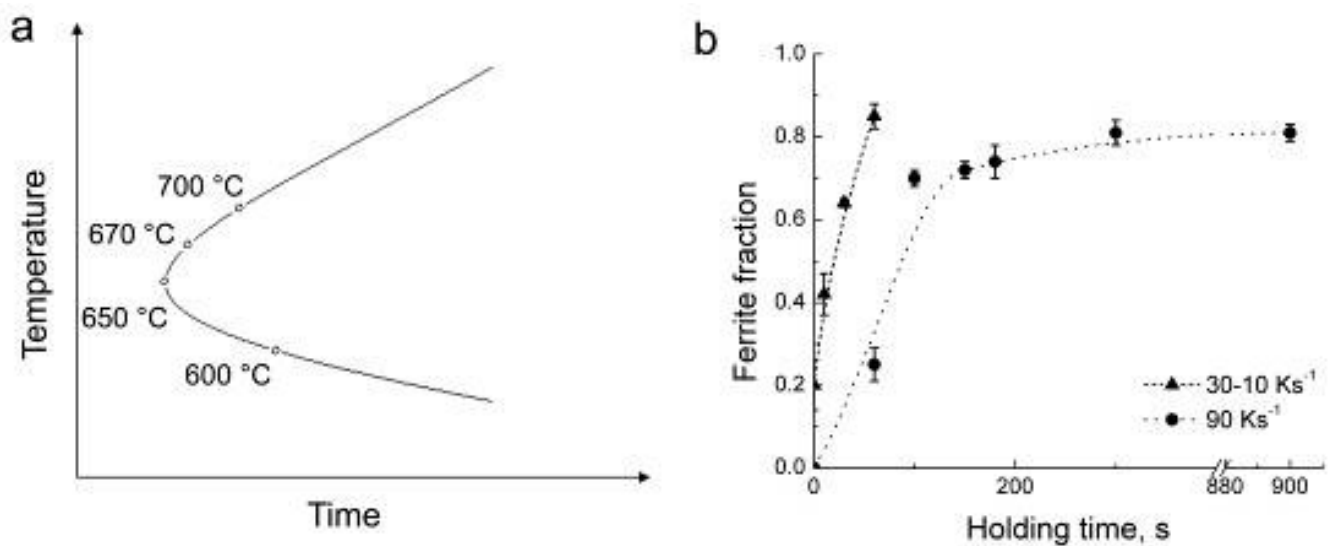

Fig.8 (a) Time-Temperature-Transformation (TTT) diagram and (b) ferrite fraction versus holding time when holding at $650^{\circ} \mathrm{C}$. 


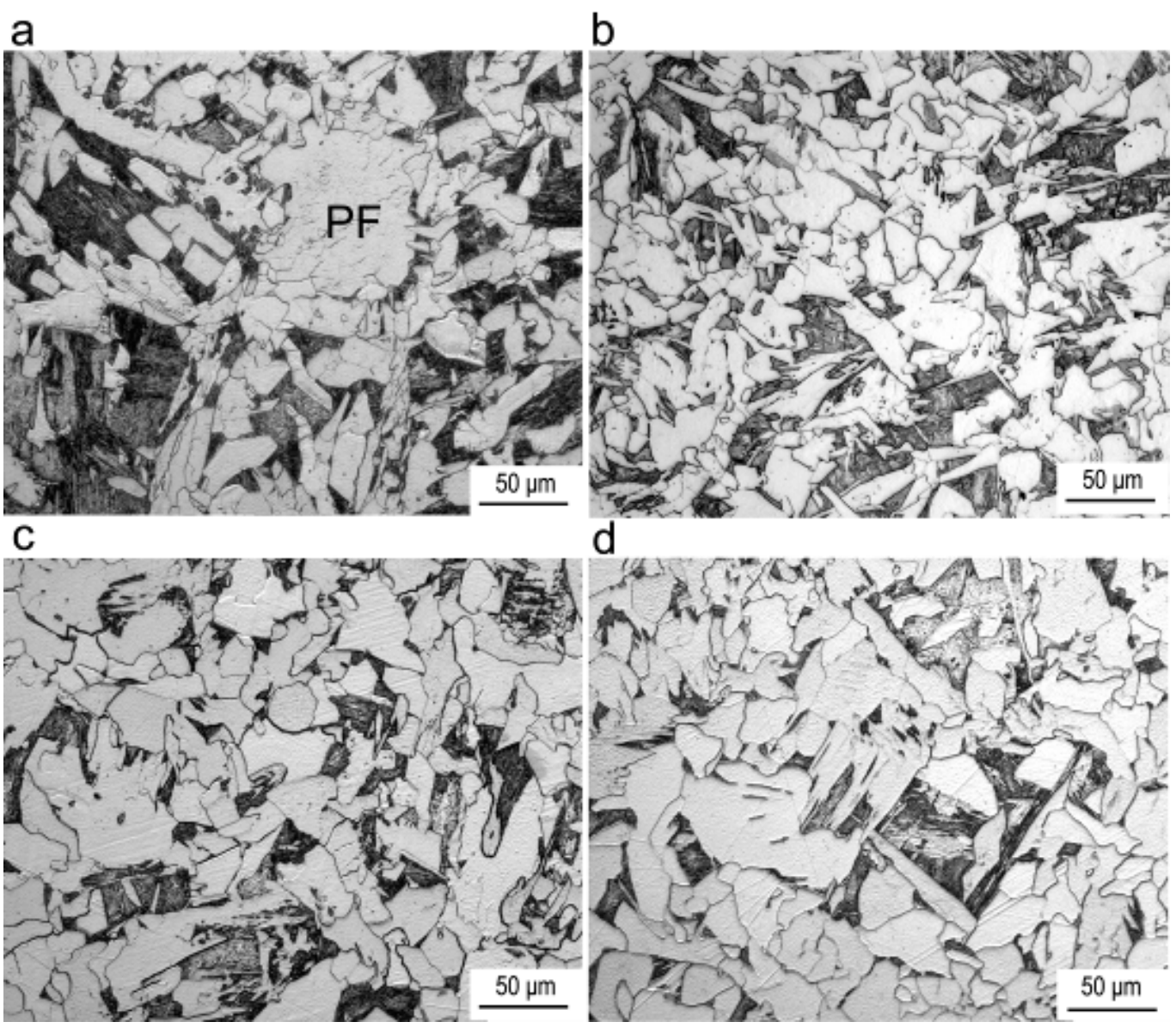

Fig.9 Optical microstructures after holding at $650{ }^{\circ} \mathrm{C}$ for (a) $30 \mathrm{~s}$, (b) $40 \mathrm{~s}$, (c) $50 \mathrm{~s}$ and (d) $60 \mathrm{~s}$. $P F$ is polygonal ferrite 


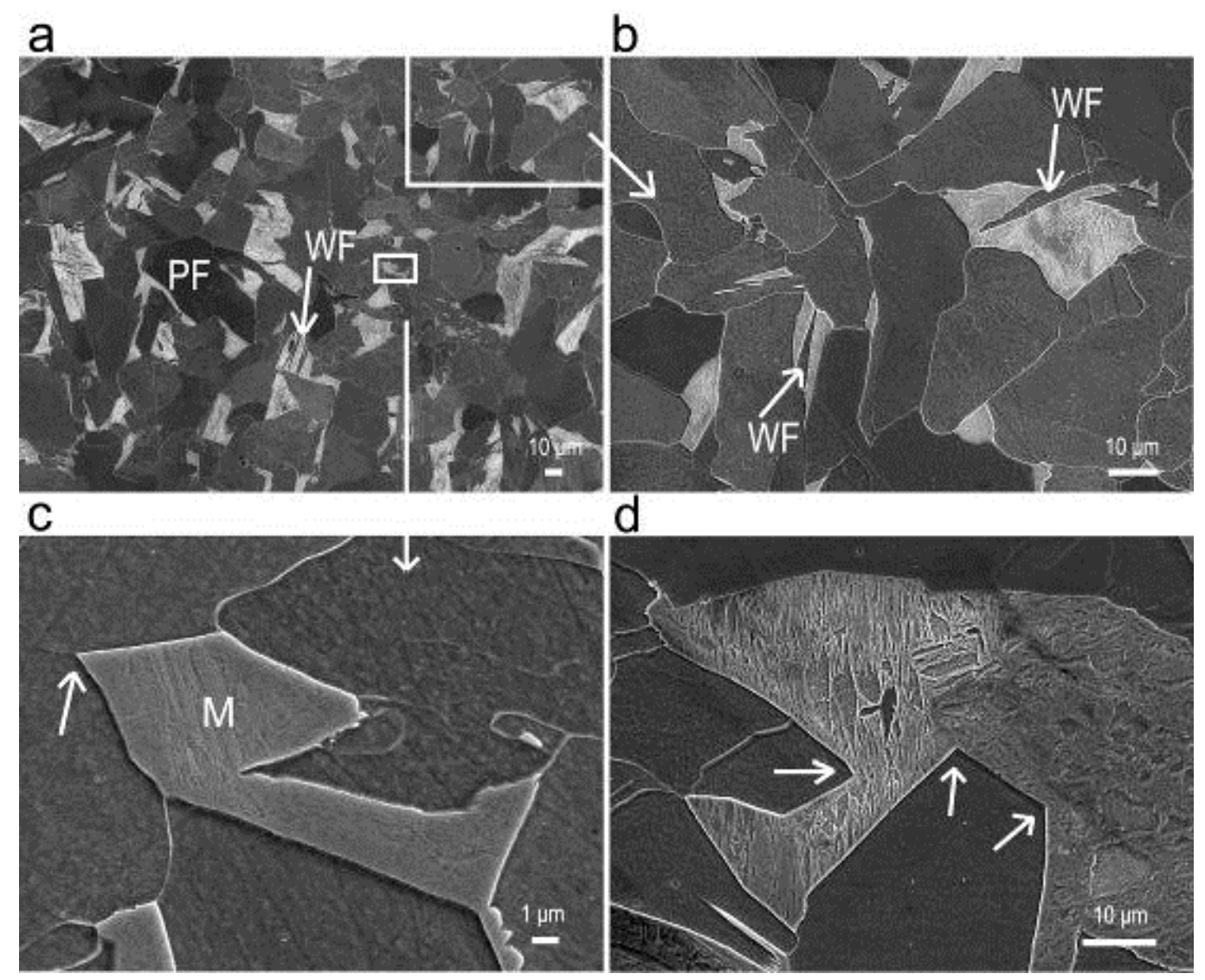

b

Fig.10 Microstructures of DP 60 characterised using scanning electron microscopy. $P F$ is polygonal ferrite, $W F$ is Widmänstatten ferrite and $M$ is martensite. Arrows in (c, d) point the concave and convex shapes of martensite regions. 
a

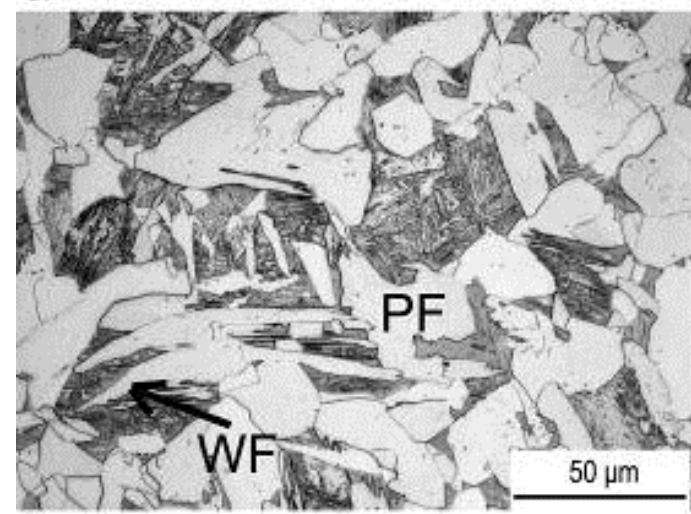

C

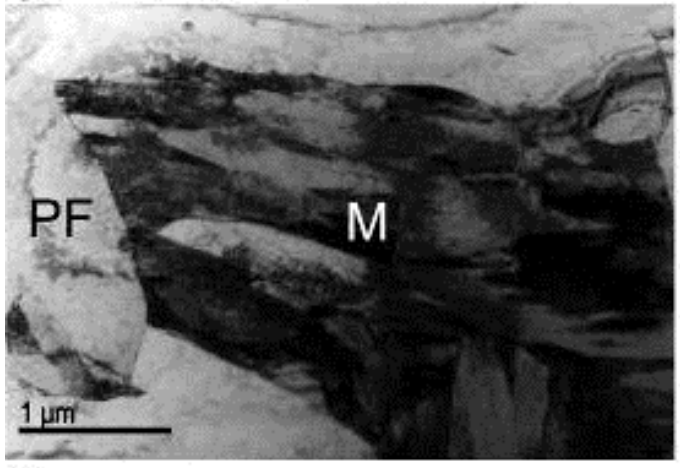

b
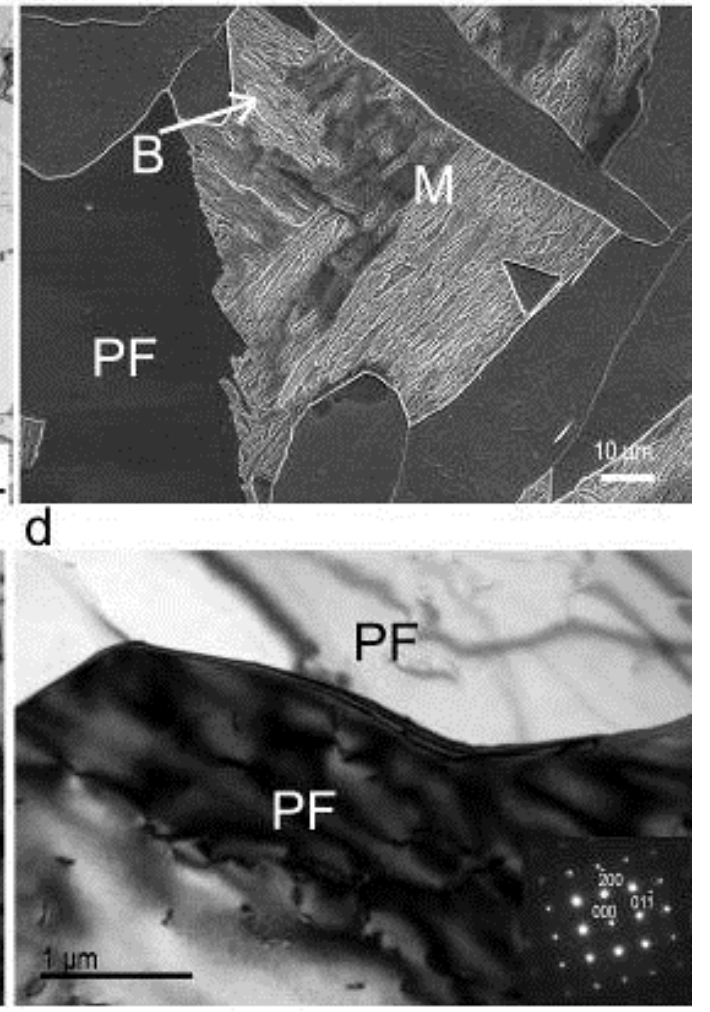

e

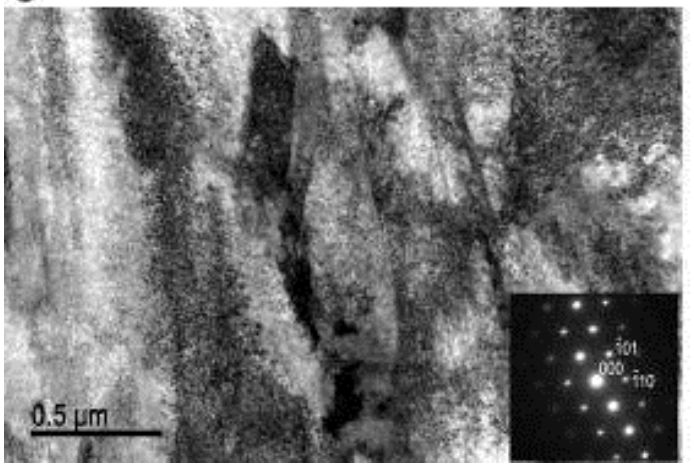

Fig.11Representative microstructures of DP 40: (a) optical, (b) SEM and (c) TEM images. Higher magnification details of polygonal ferrite and lath martensite are shown in (d) and (e) respectively. $P F$ is polygonal ferrite, $W F$ is Widmänstatten ferrite, $B$ is bainite and $M$ is martensite. The zone axis of inset in (d) is [001] $]_{\alpha}$ and of inset in (c, e) is $[111]_{\alpha}$. 


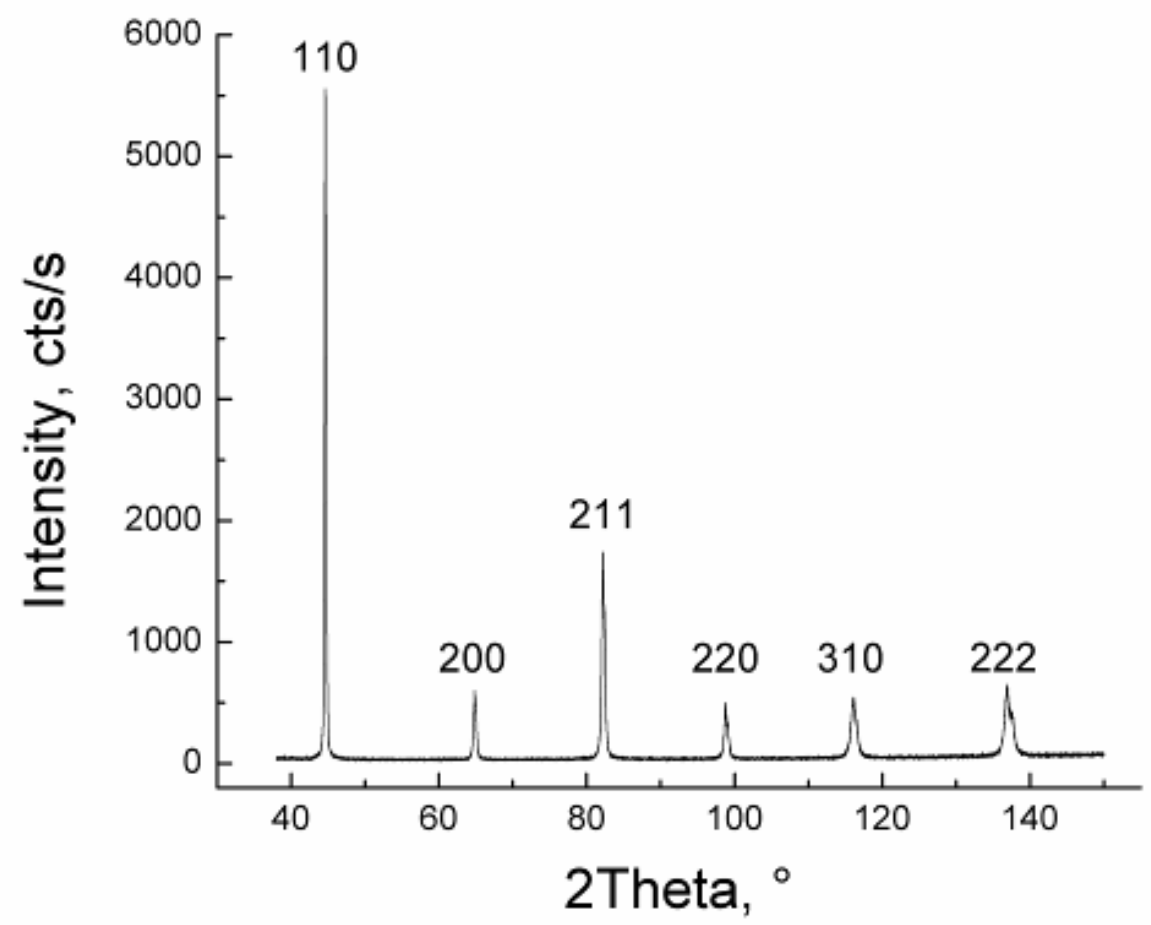

Fig.12X-ray diffraction pattern of DP 40 sample 
a

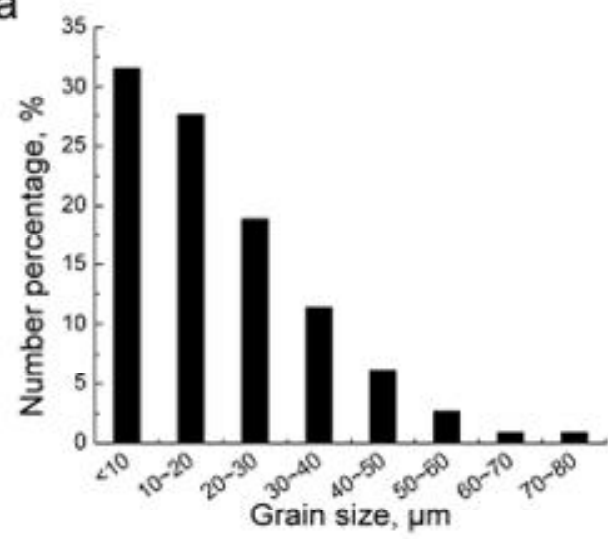

C

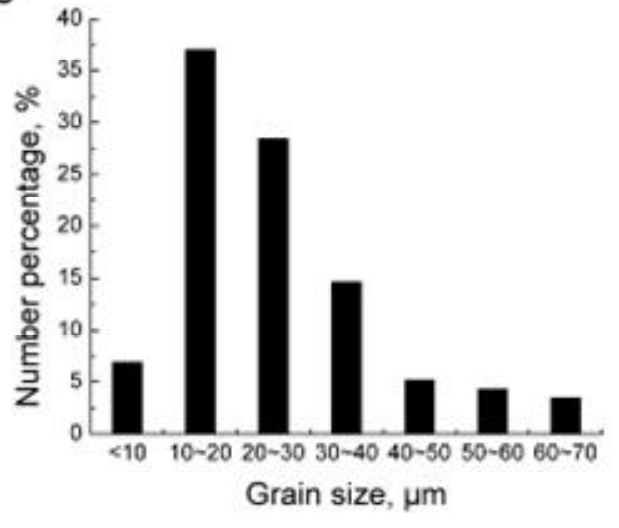

b

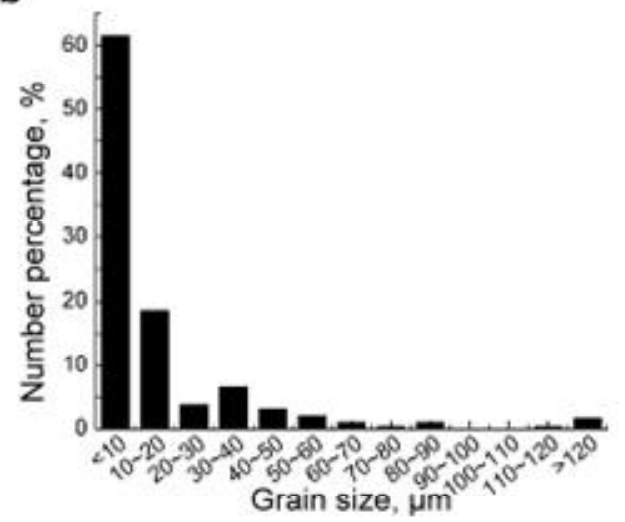

d

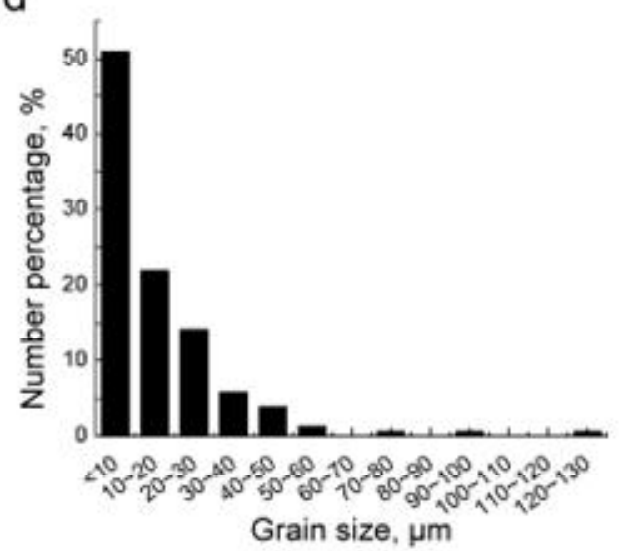

Fig.13The size distributions of (a, c) ferrite grains and (b, d) martensite regions for (a, b) DP 30 and (c, d) DP 60 . 
a

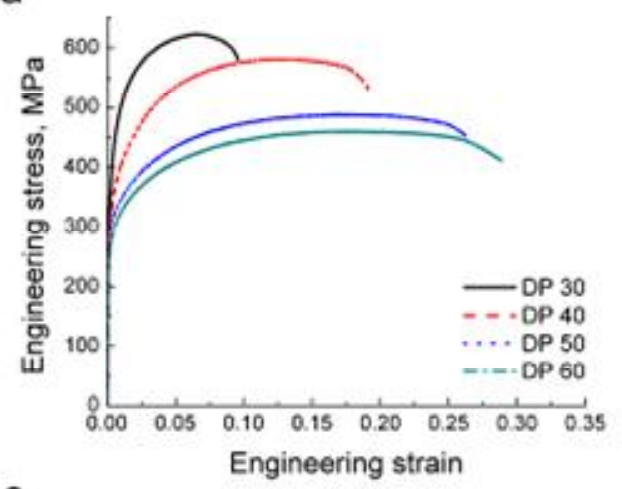

$\mathrm{C}$

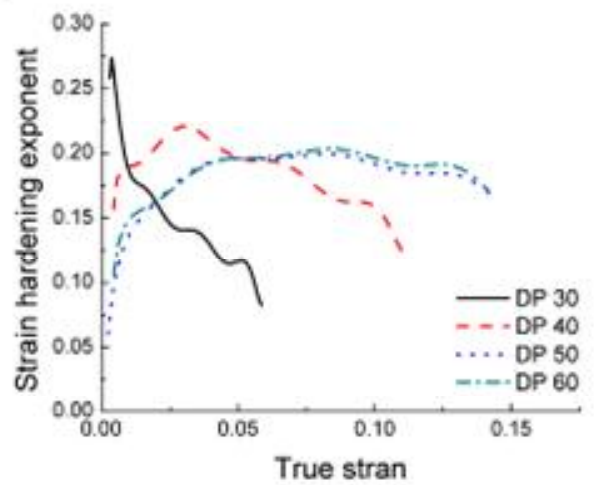

b

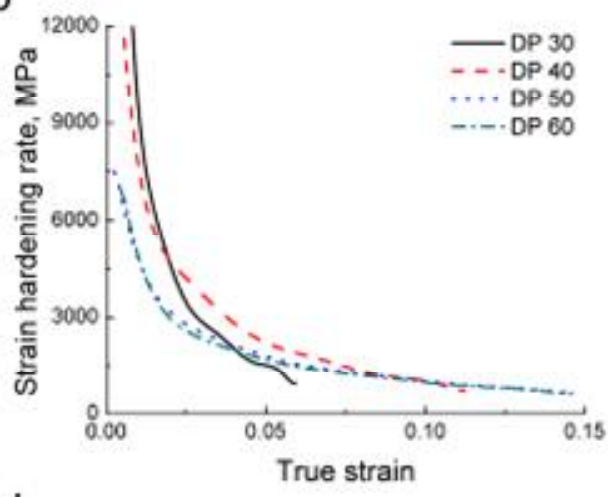

d

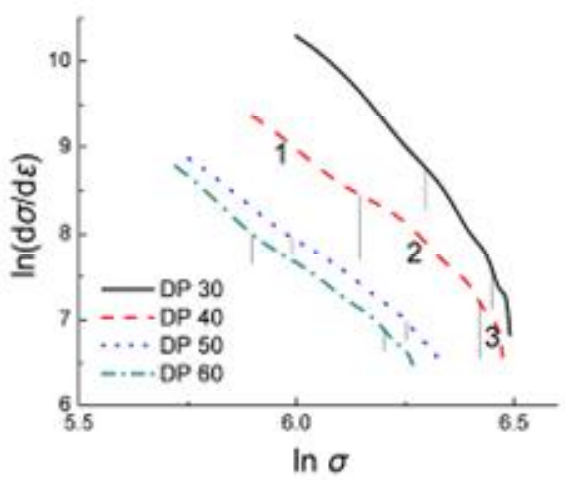

Fig.14 (a) Engineering stress-strain curves for all studied conditions, (b) strain hardening rate and (c) instantaneous strain hardening exponent $\mathrm{n}$ as a function of true strain, and (d) strain hardening behaviours based on the modified Crussard-Jaoul model analysis, where three distinct stages of strain hardening were denoted by the vertical lines and numbers. 

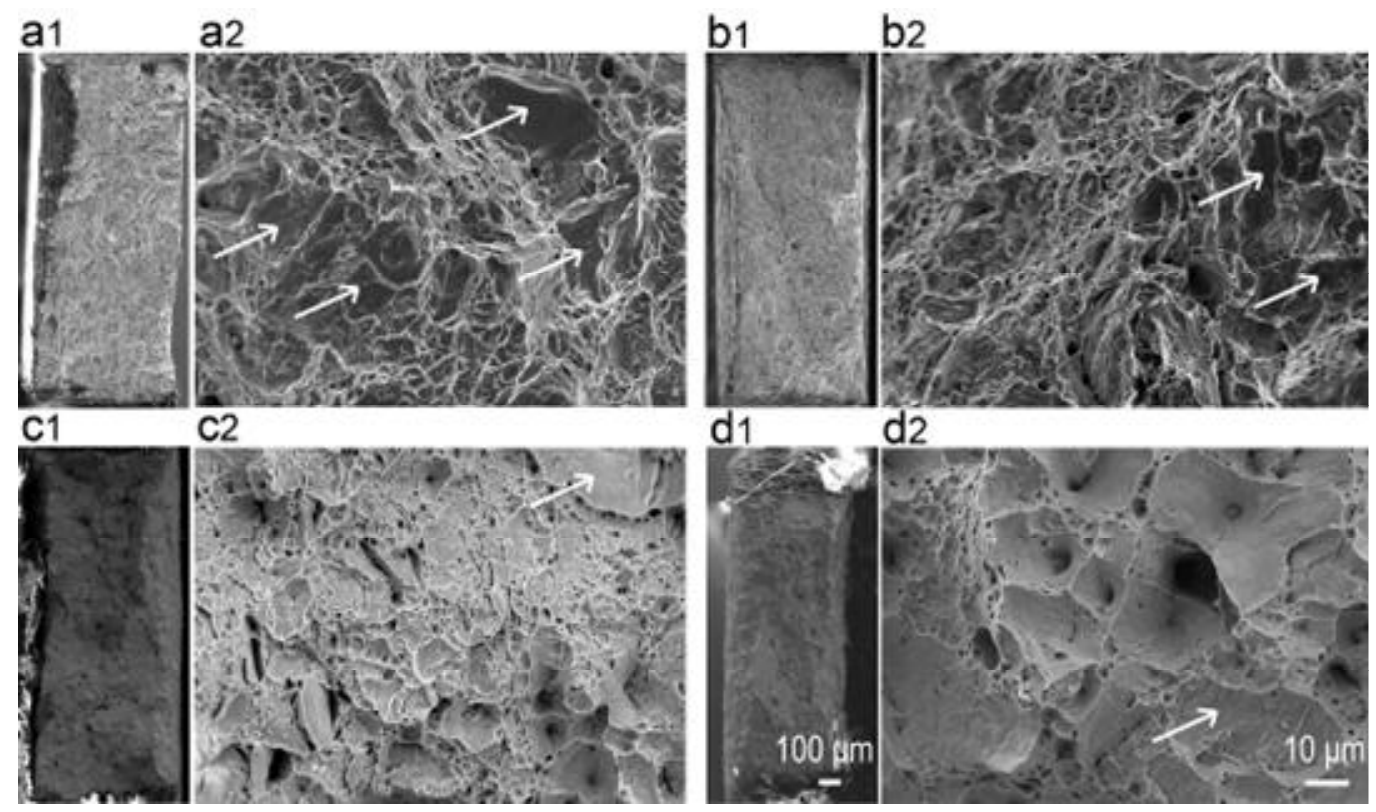

Fig.15 The macroscopic (a1 - d1) and microscopic (a2 - d2) fractography of (a) DP 30, (b) DP 40, (c) DP 50 and (d) DP 60. Arrows indicate cleavage facets. 


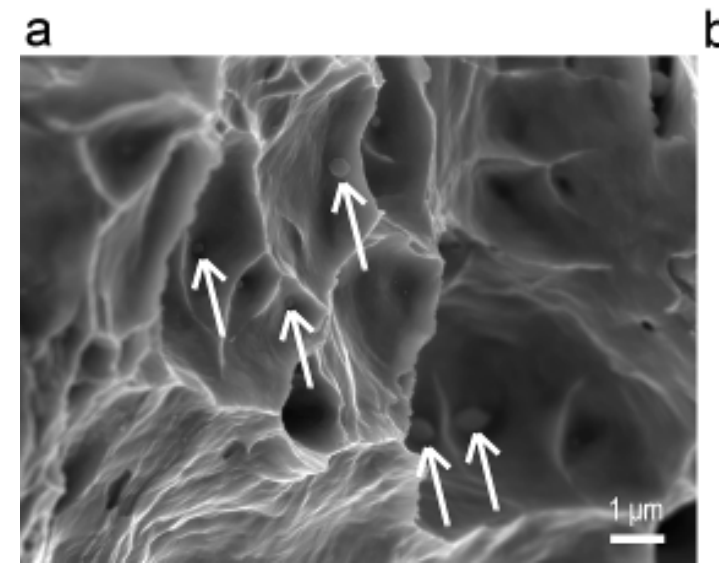

b

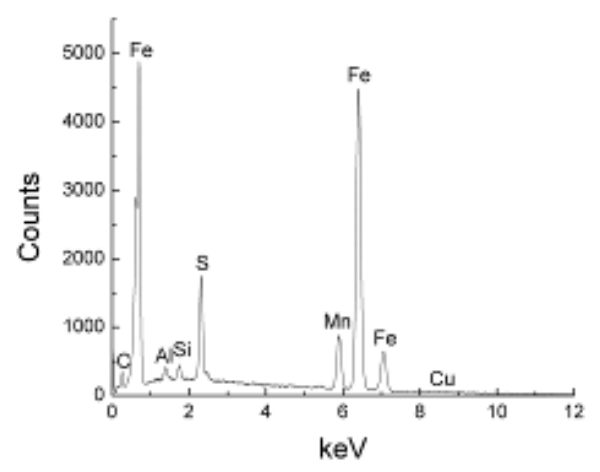

Fig.16 (a) Selected SEM image showing MnS inclusions in voids and (b) the representative EDS spectrum of MnS in DP 60. Arrows show some inclusions. 


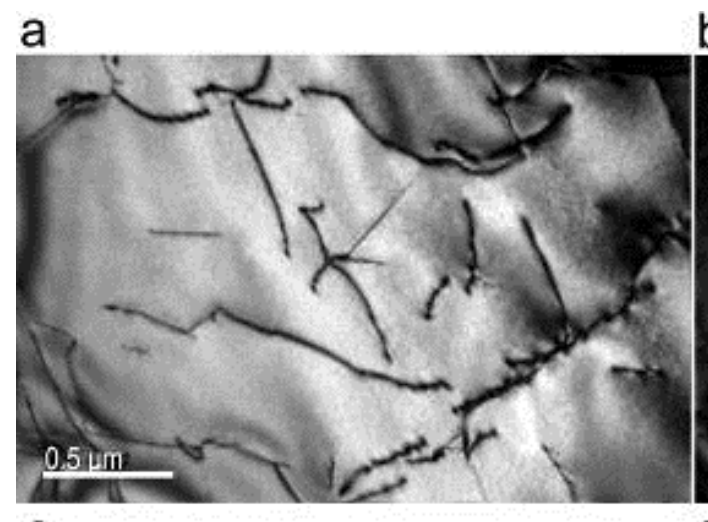

b

C
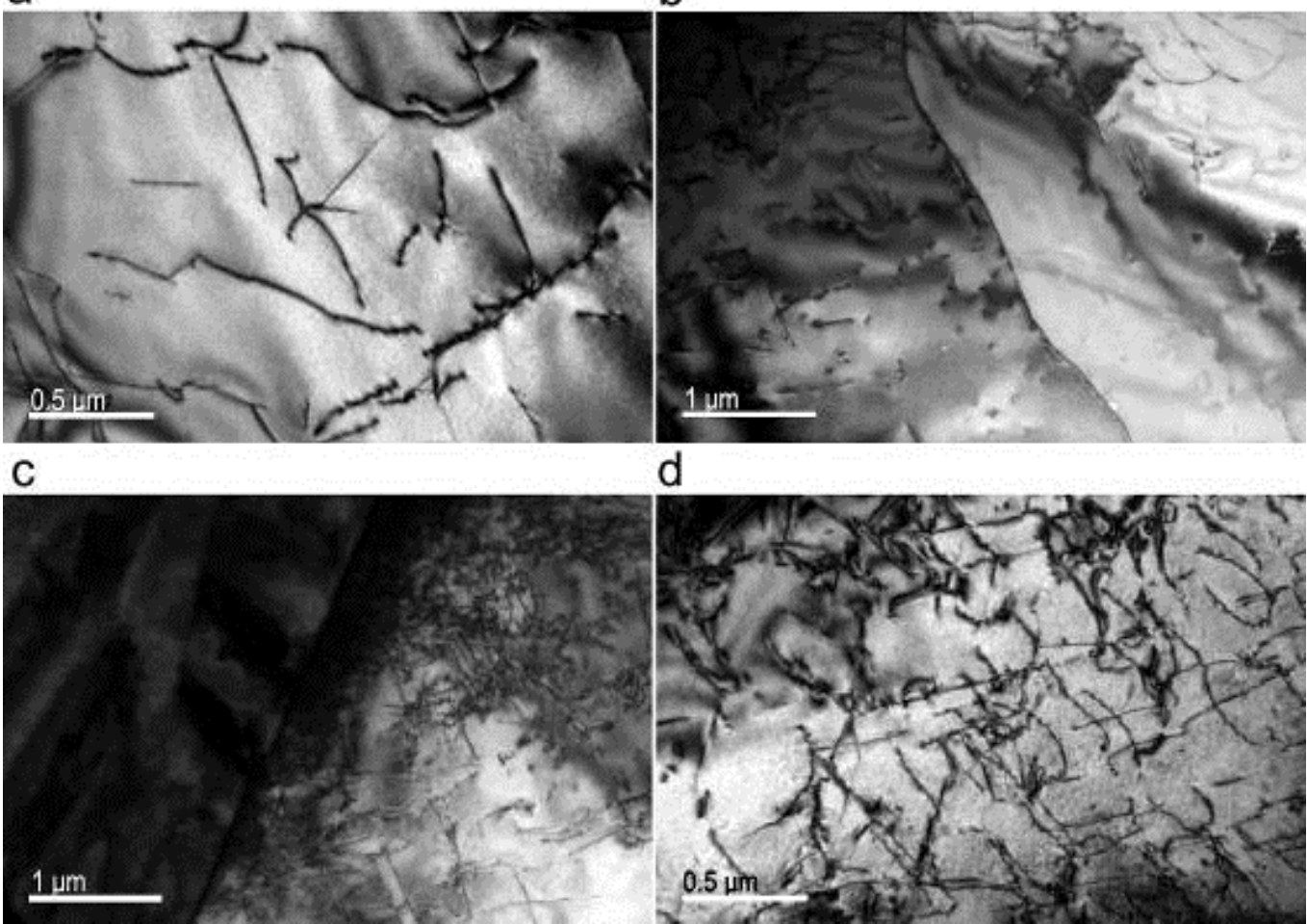

d

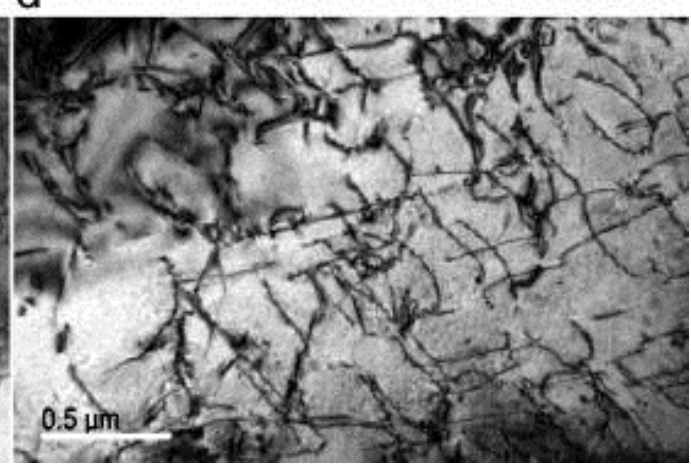

Fig.17 Selected TEM micrographs of dislocation structure for DP 60: (a) in polygonal ferrite far from grain boundaries, (b) in the region near ferrite - ferrite grain boundary, and (c) in ferrite adjacent to martensite and (d) a higher magnification of ferrite shown in (c). 

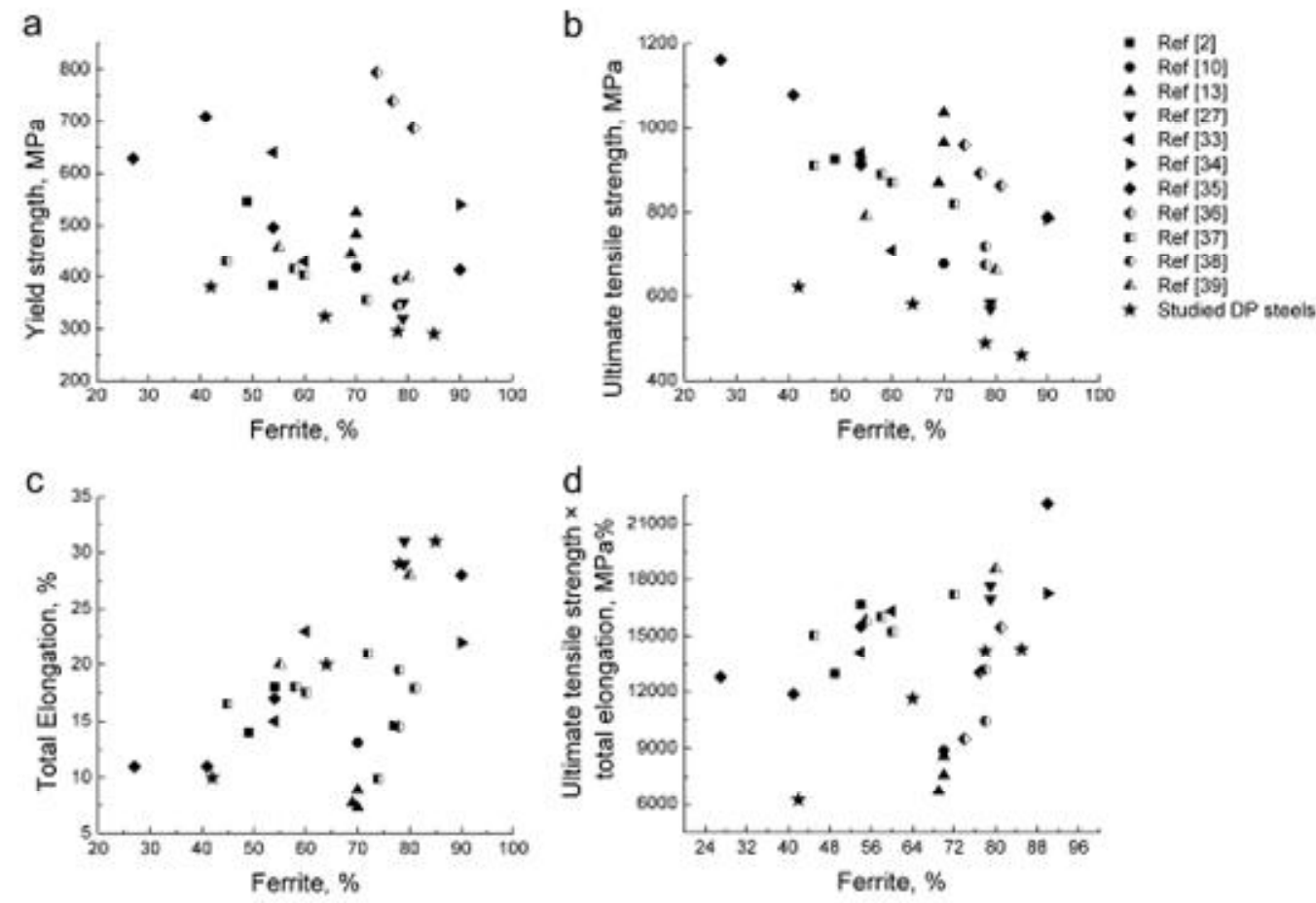

Fig.18 Comparison of the mechanical properties of studied steels with the properties of hot rolled DP steels [2, 10, 13, 27, 33-39]: (a) yield strength, (b) ultimate tensile strength, (c) total elongation and (d) ultimate tensile strength $\times$ total elongation. 
Table 1 Chemical composition of the DP steel (wt. \%).

\begin{tabular}{ccccccccc}
\hline $\mathrm{C}$ & $\mathrm{Si}$ & $\mathrm{Mn}$ & $\mathrm{Al}$ & $\mathrm{Cu}$ & $\mathrm{Cr}$ & $\mathrm{P}$ & $\mathrm{S}$ & $\mathrm{B}$ \\
\hline 0.0768 & 0.805 & 1.47 & 0.0346 & 0.0126 & 0.233 & 0.0055 & $<0.00050$ & 0.00091 \\
\hline
\end{tabular}

Table 2 A summary of microstructure statistics

\begin{tabular}{cccccccc}
\hline \multirow{2}{*}{ Specimen } & Ferrite & \multicolumn{2}{c}{ Average size, $\mu \mathrm{m}$} & \multicolumn{2}{c}{ Largest size, $\mu \mathrm{m}$} & \multicolumn{2}{c}{ Smallest size, $\mu \mathrm{m}$} \\
\cline { 3 - 7 } & fraction & Ferrite & Martensite & Ferrite & Martensite & Ferrite & Martensite \\
\hline DP 30 & $0.42 \pm 0.06$ & $20 \pm 15$ & $17 \pm 30$ & 77 & 243 & 2 & 3 \\
DP 40 & $0.64 \pm 0.05$ & $17 \pm 10$ & $10 \pm 9$ & 60 & 59 & 4 & 3 \\
DP 50 & $0.78 \pm 0.01$ & $18 \pm 10$ & $12 \pm 13$ & 59 & 99 & 4 & 3 \\
DP 60 & $0.85 \pm 0.03$ & $25 \pm 14$ & $16 \pm 17$ & 69 & 91 & 5 & 3 \\
\hline
\end{tabular}

Table 3 Mechanical properties of DP steels

\begin{tabular}{cccccc}
\hline Specimen & $\begin{array}{c}\text { Yield strength, } \\
\mathrm{MPa}\end{array}$ & $\begin{array}{c}\text { Ultimate } \\
\text { tensile } \\
\text { strength, MPa }\end{array}$ & $\begin{array}{c}\text { Uniform } \\
\text { elongation }\end{array}$ & $\begin{array}{c}\text { Total } \\
\text { elongation }\end{array}$ & $\begin{array}{c}\text { Product of ultimate } \\
\text { tensile strength and total } \\
\text { elongation, MPa\% }\end{array}$ \\
\hline DP 30 & $381 \pm 28$ & $623 \pm 26$ & $0.063 \pm 0.007$ & $0.10 \pm 0.011$ & 6230 \\
DP 40 & $324 \pm 17$ & $582 \pm 11$ & $0.13 \pm 0.001$ & $0.20 \pm 0.018$ & 11640 \\
DP 50 & $295 \pm 21$ & $489 \pm 4$ & $0.17 \pm 0.001$ & $0.29 \pm 0.008$ & 14181 \\
DP 60 & $290 \pm 16$ & $461 \pm 8$ & $0.17 \pm 0.005$ & $0.31 \pm 0.001$ & 14291 \\
\hline
\end{tabular}

Table 4 Comparison of the modified Crussard - Jaoul (C-J) analysis with the experimental results

\begin{tabular}{ccccc}
\hline \multirow{2}{*}{ Specimen } & \multicolumn{3}{c}{ Modified C-J model } & Experimental $m^{\mathrm{b}}$ \\
\cline { 2 - 4 } & $m_{1}{ }^{\mathrm{a}}$ & $m_{2}$ & $m_{3}$ & 16.4 \\
DP 30 & 6.4 & 8.7 & 16.4 & 8.2 \\
DP 40 & 4.9 & 6.0 & 11.0 & 6.1 \\
DP 50 & 5.0 & 4.9 & 7.0 & 6.2 \\
DP 60 & 5.5 & 4.8 & 6.9 & \\
\hline
\end{tabular}

${ }^{\mathrm{a}} 1-m_{1-3}=$ slopes at Stage 1 to 3

${ }^{\mathrm{b}} m=1 /\left(\varepsilon_{\mathrm{u}}-\varepsilon_{\mathrm{y}}\right)$, where $\varepsilon_{\mathrm{u}}$ is maximum uniform true strain and $\varepsilon_{\mathrm{y}}$ is true strain at $0.2 \%$ offset proof stress 